\title{
ESTUDO DA TRATABILIDADE DE EFLUENTE DA INDÚSTRIA FARMACÊUTICA POR MEIO DOS FUNGOS Pycnoporus sanguineus, Schizophyllum comnune E FOTOCATÁLISE
}

\author{
STUDY OF TRACTABILITY OF PHARMACEUTICAL EFFLUENT BY FUNGI Pycnoporus \\ sanguineus, Schizophyllum commune AND PHOTOCATALYSIS
}

\author{
Paulo de Tarso Ferreira Sales ${ }^{1}$, Luiza Cintra Campos ${ }^{2}$, Fernando Schimidt ${ }^{3}$, Marize Campos Valadares ${ }^{4}$, \\ Mariângela Fontes Santiago ${ }^{5}$
}

Recebido em 29 de agosto de 2012; recebido para revisão em 05 de setembro de 2012; aceito em 18 de setembro de 2012; disponivel on-line em 17 de outubro de 2012.

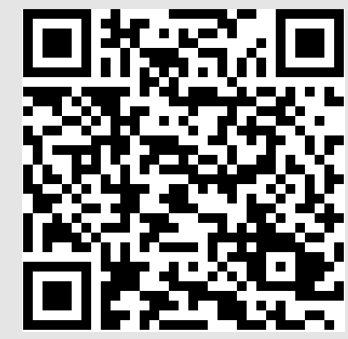

PALAVRAS CHAVES:

Efluente da indústria farmacêutica;

Pycnoporus sanguineus;

Schizophyllum commune;

Fotocatálise.

\section{KEYWORDS:}

Pharmaceutical industry effluent;

Pycnoporus sanguineus;

Schizophyllum commune; Photocatalysis;

ISSN: 2179-0612

$1,2,3,4,5$ Contato com os autores na página seguinte
RESUMO: O presente trabalho tem por objetivo avaliar a tratabilidade de um efluente da indústria farmacêutica, por meio dos fungos Pycnoporus sanguineus e Schizophyllum comnune e a fotocatálise heterogênea, usando-se o $\mathrm{TiO}_{2}$. Foram avaliadas a produção enzimática de lacase, manganês peroxidase, lignina peroxidase, a variação da Demanda Química de Oxigênio (DQO) e a toxicidade a Artemia salina. Foi usado o meio de cultura sólido ágar batata (BGA) para o crescimento dos fungos (cinco dias); contudo, houve uma variação: a substituição da água destilada pelo efluente in natura para indução enzimática. Foram realizados tratamentos biológico e combinado com fotocatálise, primeiramente tratamento biológico inicial seguido de fotocatálise e depois fotocatálise seguida de tratamento biológico. Verificou-se maior redução de $78 \%$ de DQO em $48 \mathrm{~h}$ de tratamento fúngico por meio de $S$. commune e maior produção de lacase $\left(17,00 \mathrm{U} \mathrm{mL}^{-1}\right)$ pelo $P$. sanguineus em $96 \mathrm{~h}$ de tratamento fúngico. As formas combinadas apresentaram decaimento de DQO e produção enzimática menor que o tratamento biológico. Em todas as formas de tratamento não houve aumento de toxicidade para Artemia salina, indicando viabilidade ambiental para o processo de tratamento biológico.

ABSTRACT: The present work intends to evaluate the tractability of a pharmaceutical effluent by Pycnoporus sanguineus, Schizophyllum commune and heterogenic photocatalysis, using $\mathrm{TiO}_{2}$ as catalyser. It was evaluated enzymatic activity of Laccase, manganese peroxidase, lignin peroxidase, chemical oxygen demand (COD) and toxicity to Artemia salina. It was used the solid culture medium with agar and potato to fungal growth (5 days), however there was a variation: the substitution of distilled water to in natura effluent to induction enzymatic. The bioremediation treatment were done with in natura effluent, sterilized effluent and induction on solid medium and the combined treatment were done with initial biologic treatment before photocatalytic treatment and the opposite of. The highest COD increasing in $48 \mathrm{~h}$ of fungal treatment were using $\mathrm{S}$. commune and the highest laccase production (17.00 $\mathrm{U}$ $\mathrm{mL}^{-1}$ ) were by Pycnoporus sanguineus in $96 \mathrm{~h}$ of treatment and manganese peroxidase production in $24 \mathrm{~h}$ of treatment $\left(2.00 \mathrm{U} \mathrm{mL}^{-1}\right)$. In general, the combined treatment showed COD decreasing and enzymatic production smaller than the biological treatment. In all treatment forms, there was no increasing of toxicity to Artemia salina, indicating environmental viability to biological treatment. 


\section{* Contato com os autores:}

1'e-mail : paulo@tecpam.com.br (P.de T. F. Sales)

Tecnólogo em Química Industrial e Mestre em Engenharia do meio Ambiente - PPGEMA/EEC/UFG

2e-mail : I.campos@ucl.ac.uk (L. C. Campos)

Profa. Dra. do Department of Civil, Environmental and Geomatic Engineering, University College London

${ }^{3}$ e-mail : schimidt99@bol.com.br (F. Schimidt)

Prof. Dr. do Instituto Federal de Goiás - IFG

${ }^{4}$ e-mail : mcvbozinis@gmail.com (M. C. Valadares)

Profa. Dra. da Faculdade de Farmácia - Universidade Federal de Goiás - UFG.

${ }^{5}$ e-mail : mariangelafs@gmail.com (M. F. Santiago)

Profa. Dra. da Faculdade de Farmácia - Universidade Federal de Goiás - UFG.

\section{INTRODUÇÃO}

A Química é um importante instrumento para o desenvolvimento sócio-econômico de um país e, partindo desse pressuposto, a síntese de novos produtos que atendam à demanda industrial foi incrementada com a finalidade de suprir as necessidades da indústria moderna. Contudo, com a industrialização, a geração de rejeitos tomou outra conotação no meio ambiente. Por exemplo, para que a indústria farmacêutica especializada em síntese orgânica produza $1 \mathrm{Kg}$ de produto final, são gerados de 25 a $100 \mathrm{~kg}$ de lixo químico (Correia et al., 2002). Mais recentemente, compostos farmacêuticos têm sido detectados no solo e na água potável, mas pouco se conhece sobre o risco imposto aos seres humanos por esta contaminação (Kümmerer, 2000). Diante destas constatações, o monitoramento de resíduos de drogas no ambiente aquático vem ganhando muito destaque (Hirsch et al., 1999). O uso de fungos capazes de degradar compostos orgânicos parece ser um método bastante promissor para o tratamento dos efluentes de origem farmacêutica, em particular, os fungos de decomposição branca que possuem um sistema enzimático extracelular capaz de tolerar altas concentrações de poluentes tóxicos (Barr e Aust, 1994; Young e Yu, 1997; Knapp e Newby, 1995; Kapdan et al., 2000; Fu e Viraraghavan, 2001; Stolz, 2001; Novotný et al., 2001; Robinson et al., 2001). Entretanto, em organismos eucariotos, os xenobióticos podem promover a alteração de sistemas enzimáticos responsáveis por processos vitais, como cita Jonsson (2005).

Segundo Kunz e colaboradores (2002), a possibilidade de usar microrganismos versáteis capazes de degradar de maneira eficiente contaminantes é de grande importância, principalmente devido ao baixo custo operacional. Outra grande vantagem é a possibilidade de uso em grandes volumes, com a total mineralização dos compostos orgânicos em $\mathrm{CO}_{2}$ e $\mathrm{H}_{2} \mathrm{O}$ (ou $\mathrm{CH}_{4}$ e $\mathrm{CO}_{2}$ ) (Freire et al., 2000). Partindo de avaliações do impacto ambiental relativo ao efluente da indústria farmacêutica, faz-se necessário estudo do processo de degradação dos contaminantes, sendo que de acordo com os princípios da química verde, que propõe o uso de catalisadores no processo de tratamento de resíduos (Prado, 2003), a biorremediação (fungos) e fotocatálise heterogênea têm grandes perspectivas no uso como técnica de mineralização de compostos recalcitrantes presentes nas águas residuárias da indústria farmacêutica. Melo e colaboradores (2006) propõem além de descontaminar o efluente, avaliar a toxicologia usando-se microrganismos (Selenastrum capricornutum). Eles também propõem um estudo de citotoxicidade, com a utilização de células (fibroblastos), a fim de melhorar a avaliação da viabilidade de processos de tratamento.

Substâncias farmacêuticas são quaisquer substâncias ou produtos usados quando se pretende modificar ou explorar sistemas fisiológicos ou estados patológicos em benefício de quem o recebe (Who, 1972). Elas são um grupo de substâncias que até recentemente vinham sendo expostas ao meio ambiente com muito pouca atenção. A partir da década de 80 encontram-se relatos de dados sobre a ocorrência destes produtos na superfície de águas naturais e nos efluentes de estações de tratamento de esgoto (Halling-Sorensen et al., 1998; HIRSCH et al., 1999). As indústrias farmacêuticas do Estado de Goiás apresentam uma produção diversificada, podendo-se citar antibióticos, antifúngicos, antigripais, broncodilatadores, antivirais, vitaminas, produtos dermatológicos, hormônios, dentre outros. Sabe-se que a indústria farmacêutica é uma das que contribui ao processo de contaminação ambiental através de seus resíduos gerados, principalmente durante os processos de síntese de fármacos que utilizam uma gama de compostos halogenados, tanto como reagente, solvente ou intermediário (New et al., 2000).

Embora compostos farmacêuticos sejam farmacologicamente e clinicamente testados, dados sobre a ecotoxicidade destes compostos ativos são geralmente limitados. Valores de toxicidade aguda são nas faixas de mg. $\mathrm{L}^{-1}$ (Halling-Sorensen et al., 1998; Webb, 2001), embora, níveis mais baixos foram detectados em 
águas superficiais, o que poderá ser possível avaliar apenas a toxicidade crônica (Webb, 2001). Antibióticos tem efeitos diferentes que os outros xenobióticos, pois seu alvo específico são as bactérias. O aumento do uso de antibióticos nas últimas cinco décadas causou uma seleção genética de bactérias mais resistentes (Jorgensen e Halling-Sorensen, 2000). Considerando que o desenvolvimento da resistência a antibióticos é favorecida pela poluição da água e sedimento (Kümmerer e Henninger, 2003). Nos últimos anos, há um crescente interesse no efeito de genotoxicidade provenientes do lançamento de compostos genotóxicos ao meio ambiente. A genotoxicidade é medida pela capacidade de substâncias danificarem o DNA e cromossomos das células. Muitas substâncias farmacêuticas são genotóxicas, como as citostáticas (Sorsa et al., 1985). Tais substâncias são muito tóxicas a humanos (mutagênico, carcinogênico e teratogênico), sendo este grupo de importante estudo para o efeito ambiental (Daughton e Ternes, 1999). A toxicidade pode mascarar a genotoxicidade, principalmente se a amostra for um agente mutagênico fraco, fazendo-se necessário o uso de teste de toxicidade e de genotoxicidade, a fim de se ter uma melhor avaliação dos resultados (Kargalioglu et al., 2002). Muitos estudos retrataram mutagenicidade de águas residuárias (Filipic e Toman, 1996; Jolibois et al., 2003; Jolibois e Guerbet, 2005) em águas superficiais (Umbuzeiro et al., 2001; Kutlu et al., 2004) e águas de abastecimento (Park et al., 2000). A ausência de atividade mutagência em efluentes já foi relatada em muitos estudos (Shishida et al., 2000; Monarca et al., 2000) e outros autores relataram a redução parcial de compostos mutagênicos por tratamentos biológicos ( $\mathrm{Hu}$ et al., 2003).

A fotocatálise heterogênea (que também pertence ao POA - Processos Oxidativo Avançados) tem mostrado grande eficiência no tratamento águas residuárias, promovendo a descoloração de efluentes e a descontaminação ambiental (Peralta-Zamora et al., 1998; Peralta-Zamora et al., 1999). O processo é baseado na irradiação (fonte de luz ultravioleta) de semicondutores inorgânicos (mais comumente o $\mathrm{TiO}_{2}$ por apresentar baixo custo). A energia do fóton é capaz de provocar a transição eletrônica de elétrons da banda de valência para a banda de condução do semicondutor, gerando sítios oxidantes e redutores capazes de catalisar reações químicas, oxidando compostos orgânicos a $\mathrm{CO}_{2}$ e $\mathrm{H}_{2} \mathrm{O}$ e reduzindo metais ou substâncias presentes nas moléculas dos poluentes. O uso de luz solar como fonte de radiação também vem sendo amplamente estudado pelo fato do $\mathrm{TiO}_{2}$ apresentar foto-atividade na luz visível.
Outros fatores favoráveis ao emprego do $\mathrm{TiO}_{2}$ são a baixa toxicidade e a elevada estabilidade em uma ampla faixa de $\mathrm{pH}$ (Nogueira e Jardim, 1998).

Experimentos realizados por Assalin et al. (1999), mostraram que o processo fotocatalítico heterogêneo e a fotólise são bastante eficientes na desinfecção de águas, sendo possível desinfetarem águas com altos teores de coliformes fecais (da ordem de $10^{7}$ $\mathrm{NMP} / 100 \mathrm{~mL}$ ). De acordo com Morais, Sirtori e PeraltaZamora (2006) o processo fotocatalítico é viável como sistema de pré-tratamento de amostras de chorume, visando aumentar sua biodegradabilidade aeróbia. Ferreira e Daniel (2004) estudaram o uso do $\mathrm{TiO}_{2}$ para o tratamento de esgoto tratado biologicamente, sendo que se utilizou como fonte de radiação UV a luz solar e o catalisador imobilizado em placa de vidro. A degradação de efluentes da indústria têxtil já foi estudada utilizando a fotocatálise usando-se $\mathrm{TiO}_{2}$ e $\mathrm{Nb}_{2} \mathrm{O}_{5}$ sob radiação visível de fonte artificial, o que pode garantir um uso industrial dessa tecnologia (Santana e Machado, 2002). Alguns estudos sobre inativação de microrganismos mostraram que a fotoinativação pode vir a representar um importante método de desinfecção, como estudado por Cordeiro, Leite e Dezotti (2004), em que se utilizou a Escherichia coli e Pseudomonas sp. como indicadores de eficiência de inativação bacteriana. Técnicas de fotocatálise eletroquimicamente assistida para tratamento de efluentes, em que o catalisador é imobilizado sobre eletrodos e aplica-se um diferencial de tensão, tentando assim diminuir o retorno do elétron durante o band gap foram estudadas por Tauchert e Peralta-Zamora (2004), He et al. (2003) e Jiang et al. (2004).

Processos combinados de fotocatálise e tratamento biorremediativo com fungos já foram utilizados para degradar 2,4,6 trinitrotolueno (Hess et al., 1998), para tratar efluente da indústria papeleira (Pedroza et al., 2006), Parra e colaboradores (2002) estudaram a degradação de isoproturon.

Teste de toxicidade aquática é um procedimento no qual as respostas de organismos aquáticos são usadas para detectar ou medir a presença ou efeito de uma ou mais substâncias, resíduos, ou fatores ambientais, isolados ou em combinação (Cardoso e Luca, 2004). O ensaio de toxicidade com Artemia salina é utilizado em diferentes experimentos comparando a mortalidade dos microcustáceos de água salgada com a substância em teste e o seu controle. Esse método serve como uma triagem acerca do potencial de toxicidade da substância em investigação, uma vez que se calcula a toxidade aguda (concentração letal média $-\mathrm{CL}_{50}$ ) da mesma, por 
meio das médias aritméticas das repetições e a regressão linear não ponderada (Mclaughlin et al., 1995). Essa metodologia já foi usada para avaliar a toxicidade de percolado de aterro sanitário (Silva, 2002), bem como um efluente tratado biologicamente com o auxílio de carvão ativado em pó (Costa et al., 2003). Um efluente da indústria coureira, tratado com processo de Fenton e Foto-Fenton, teve a toxicidade avaliada pela referida metodologia (Dantas et al., 2003). Também já foi avaliada a toxicidade de compostos, como flavonóides (Moreira et al., 2003) e triazina (Cavalcante et al., 2000).

Este trabalho visa avaliar a tratabilidade combinada de um efluente da indústria farmacêutica, por meio dos fungos Pycnoporus sanguineus e Schizophyllum comnune e a fotocatálise heterogênea, usando-se $\mathrm{O} \mathrm{TiO}_{2}$ disperso como catalisador. Foram avaliadas a produção enzimática de lacase, manganês peroxidase e lignina peroxidade, a variação da Demanda Química de Oxigênio (DQO) e a toxicidade avaliada por Artemia salina.

\section{METODOLOGIA}

\subsection{COLETA DE EFLUENTE}

Foi coletada uma amostra simples de 20,00 L de efluente proveniente da indústria farmacêutica e mantida a 40 C (SANTIAGO, 1999). O efluente coletado era específico da área de produção de medicamentos de uma indústria farmacêutica da região de Goiânia (GO) e o local de retirada de amostra foi de uma caixa de inspeção, localizada antes do lançamento na estação de tratamento de efluentes da indústria.

\subsection{MICRORGANISMOS}

Pycnoporus sanguineus (PS) Schizophyllum comnune (SC), sendo que o primeiro fungo foi cedido pela Fundação Tropical André Tosello (Campinas, SP) e outro pelo IBAMA (Brasília, DF). Foram mantidos em meio de extrato de malte $2 \%(\mathrm{P} / \mathrm{V})$, a $4^{\circ} \mathrm{C}$.

\subsection{MEIO DE CULTURA MEIO ÁGAR BATATA (BGA)}

$50,00 \mathrm{~mL}$ de caldo de batata, 5,00 g de glicose, 3,75 g de ágar e água destilada ou efluente completado para $250,00 \mathrm{~mL}$.

\subsection{CONDIÇÕES DE CRESCIMENTO DA CULTURA}

O meio sólido foi colocado em placas de Petri $(10,00 \mathrm{~cm}$ de diâmetro) contendo $15,00( \pm 1) \mathrm{mL}$ de meio ágar-batata. Cada placa foi inoculada com disco $(5 \mathrm{~mm}$ de diâmetro) de micélio de cada fungo e meio ágarbatata, de idade de crescimento de 5 dias, à temperatura ambiente (em torno de 28 을) e no escuro, exceto o Pycnoporus sanguineus, que cresceu em temperatura constante de $370 \mathrm{C}$ (em estufa).

\subsection{MÉTODOS ANALÍTICOS E BIOLÓGICOS DE CARACTERIZAÇÃO}

Para avaliação do efluente in natura e do efluente tratado de indústria farmacêutica foram empregados os seguintes parâmetros: $\mathrm{pH}$, Turbidez, Cor, Acidez, Alcalinidade, Dureza, Ferro, Manganês, Cloro, Oxigênio Consumido, Demanda Química de Oxigênio (DQO), Demanda Bioquímica de Oxigênio (DBO), Fenol, Nitrogênio total e Fosfatos. Todas as análises foram efetuadas de acordo como o Standard Methods, Water and Wastewater 20 ${ }^{\text {th }}$ Edition, 1998 (APHA/AWWA, 1995). Os equipamentos utilizados foram Turbidímetro Tecnal modelo D-20, Espectrofotômetro marca Micronal modelo B-582, Potenciômetro marca Tecnal modelo Tec3-MP com eletrodo de $\mathrm{Ag} / \mathrm{AgCl}$, Colorímetro marca Orbeco modelo DR-850 e mesa agitadora refrigerada New Brunswick Scientific, modelo C24KC. O Digestor para realização de DQO foi o da marca Hach (COD Reactor). A estufa para cultura de microrganismos era da marca Alfa.

\subsection{DETERMINAÇÃO DAS ATIVIDADES ENZIMÁTICAS ANTES E APÓS O TRATAMENTO DO EFLUENTE COM FUNGOS}

a) Lacase (SZKLARZ et al., 1989 - modificado): A atividade de lacase foi determinada utilizando seringaldazina como substrato enzimático $\left(\varepsilon_{525 \mathrm{~nm}}=\right.$ $65.000 \mathrm{mmol} \cdot \mathrm{L}^{-1} \cdot \mathrm{cm}^{-1}$ ). A atividade enzimática foi expressa em U. $\mathrm{mL}^{-1}$ (unidades por mililitro).

b) Manganês-peroxidase (KUMAHARA et al., 1984): A mistura de reação $(1,0 \mathrm{~mL})$ continha $0,5 \mathrm{~mL}$ de caldo filtrado, 0,1 mL de lactato de sódio $0,25 \mathrm{mmol}^{-1}, 0,2 \mathrm{~mL}$ de albumina bovina 0,5\%, 0,05 $\mathrm{mL}$ de $\mathrm{MnSO}_{4} 2,0$ mmol. $\mathrm{L}^{-1}, 0,05 \mathrm{~mL}$ de uma solução de $\mathrm{H}_{2} \mathrm{O}_{2} 2,0 \mathrm{mmol} . \mathrm{L}^{-1}$ preparada em tampão succinato de sódio $0,2 \mathrm{~mol}^{-1}(\mathrm{pH}$ 4,5 ) e $0,1 \mathrm{~mL}$ de vermelho de fenol $0,1 \%$. A mistura foi incubada a $30^{\circ} \mathrm{C}$ durante $5 \mathrm{~min}$ e a reação foi interrompida pela adição de $40 \mu \mathrm{L}$ de $\mathrm{NaOH} \quad 2,0$ mmol. $L^{-1}$. A absorvância foi lida a $610 \mathrm{~nm}$ e a atividade de Manganês-peroxidase expressa como $\Delta$ Abs $\mathrm{mL}^{-1}$ $\min ^{-1}$.

c) Lignina-Peroxidase (TIEN E KIRK, 1984, modificado): A atividade de lignina peroxidase foi determinada pela 
oxidação do álcool veratrílico $\left(\varepsilon_{310 \mathrm{~nm}}=9.300 \mathrm{mmol}^{-1}\right.$. $\left.\mathrm{cm}^{-1}\right)$. A atividade enzimática foi expressa em U.mL $\mathrm{mL}^{-1}$ (unidades por mililitro).

\subsection{Ensaio de Toxicidade com Artemia salina}

Os ensaios de toxicidade aguda foram realizados conforme método modificado de Matthews (1995). Cistos de Artemia salina foram incubados durante 24 horas em solução de sal marinho sintético (38 g.L $\left.\mathrm{L}^{-1}\right)$, com aeração e iluminação constantes (1000 lux) e a uma temperatura de 25-28으. C. Após a eclosão, dez larvas do microcrustáceo foram incubadas, em tubos falcon, durante 24 horas à $25 \circ \mathrm{C}$, na ausência de luz. Após o tratamento, uma solução foi feita com $100 \mu \mathrm{L}$ do efluente bruto, em 5,0 mL de solução salina. Em seguida $0,5 \mathrm{~mL}$ dessa solução foi colocada nos tubos falcon e diluídas em $5,0 \mathrm{~mL}$ de solução salina ( $\left.38 \mathrm{~g} \cdot \mathrm{L}^{-1}\right)$.

Após 24 de incubação, foi feita a contagem do número de larvas mortas. Para cada fungo testado foram realizadas triplicatas com 10 larvas em cada. As larvas foram consideradas mortas quando não exibiram nenhum movimento interno ou externo durante 10 segundos de observação.

\subsection{REALIZAÇÃO DOS TRATAMENTOS}

Para o tratamento biológico do efluente da indústria farmacêutica, foram colocados $100,00 \mathrm{~mL}$ de efluente em um Erlenmeyer de $250 \mathrm{~mL}$, onde em capela de fluxo laminar foram colocados os conteúdos das placas (meio de cultura mais fungo) nos Erlenmeyers, sendo que todo o experimento foi feito em duplicata e que foram para controle, $24 \mathrm{~h}, 48 \mathrm{~h}, 72 \mathrm{~h}$ e $96 \mathrm{~h}$. Posteriormente, foram colocados em uma mesa agitadora refrigerada e mantidos a $28^{\circ}$ C e $180 \mathrm{rpm}$ (rotações por minuto). Para controle, foram adicionadas as culturas dos fungos, sob as mesmas condições citadas, autoclavado a uma temperatura de $121^{\circ} \mathrm{C}$ por 15 min e posteriormente seguiu-se a mesma metodologia de tratamento. Como garantia de que os compostos fúngicos foram responsáveis pelo tratamento do efluente e não a biota de origem bacteriana, o efluente foi autoclavado durante $15 \mathrm{~min}$, a $121^{\circ} \mathrm{C}$ e os resultados foram anotados. O processo físico de esterilização foi escolhido devido à menor alteração dos compostos orgânicos presentes no efluente, pois o processo químico, como a adição de hipoclorito de sódio, alteraria consideravelmente as características químicas do efluente, sendo que muitas análises físico-químicas seriam prejudicadas na precisão da metodologia, além de inviabilizar o tratamento com fungos. O tratamento pelo processo fotocatalítico foi efetuado no reator de capacidade total de $500 \mathrm{~mL}$ (Figura 1). No reator fotocatalítico foi borbulhado ar a uma vazão de $180 \mathrm{~mL}$ $\mathrm{min}^{-1}$, sendo este reator era provido de sistema de refrigeração, agitador magnético, $\mathrm{TiO}_{2}$ em suspensão (Degussa P-25), tubo de quartzo e lâmpada de alta pressão de mercúrio (Philignina peroxidase s HPL-N 125 $\mathrm{W}$, fluência de $31,1 \mathrm{~J} \mathrm{~m}^{2} \mathrm{~s}^{-1}, \lambda_{\text {máx }}=254 \mathrm{~nm}$ ) sem o invólucro externo.

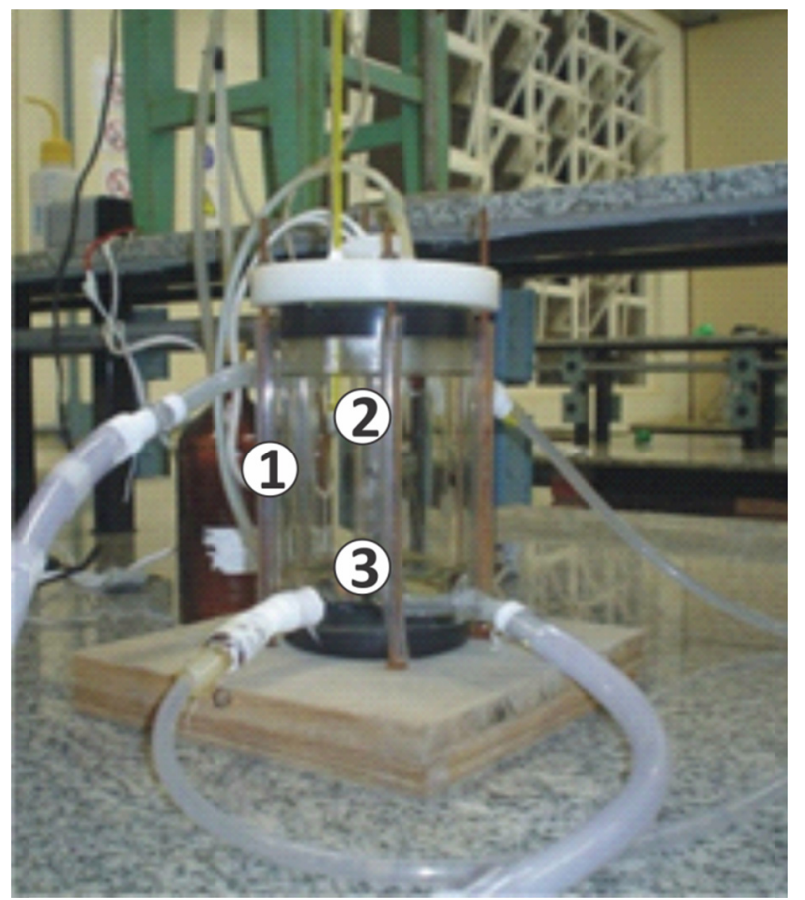

Figura 1: Esquema do reator fotocatalítico: (1) jaqueta de água para controle de temperatura; (2) tubo de quartzo para lâmpada; e (3) barra de agitador magnético.

\section{RESULTADOS E DISCUSSÃO}

A Tabela 1 relaciona as características físicoquímicas e bioquímicas das amostras em estudo. As amostras 2, 3 e 4 foram coletadas, caracterizadas e tratadas biologicamente, entretanto, por não terem apresentado viabilidade de tratamento com fungos (devido à presença de antifúngicos e sanitizantes), os dados sobre sua tratabilidade não serão mostrados.

De acordo com dados da própria indústria, o efluente gerado é basicamente proveniente do processo de lavagem dos misturadores, sendo que os sanitizantes fazem parte do efluente, bem como os resíduos da produção, que em sua maioria é de antibióticos, injetáveis, soros, antifúngicos, xaropes e analgésicos. 
Tabela 1: Análises de características dos efluentes líquidos da indústria farmacêutica.

\begin{tabular}{|c|c|}
\hline Característica & Valor \\
\hline Turbidez - NTU & 59,0 \\
\hline $\mathrm{pH}$ & 2,7 \\
\hline Absorbância em 400 nm & 0,077 \\
\hline Cor $-\mathrm{mg} \cdot \mathrm{L}^{-1}$ de Pt/Co & 403,0 \\
\hline Acidez - mg de acidez & 188,00 \\
\hline Alcalinidade - $\mathrm{mg}$ de $\mathrm{CaCO}_{3} \mathrm{~L}^{-1}$ & N.D. \\
\hline Dureza Total - mg. $\mathrm{L}^{-1}$ & N.D. \\
\hline Ferro - $m g \cdot L^{-1}$ & 1,15 \\
\hline Manganês - $m g \cdot \mathrm{L}^{-1}$ & 1,10 \\
\hline Oxigênio dissolvido $\mathrm{mg}^{-\mathrm{L}^{-1}}$ & 3,10 \\
\hline Fosfatos - mg. $\mathrm{L}^{-1}$ & 10,00 \\
\hline Nitrogênio total - mg. $\mathrm{L}^{-1}$ & 1,00 \\
\hline $\mathrm{DQO}-\mathrm{mg}$ de $\mathrm{O}_{2} \cdot \mathrm{L}^{-1}$ & 263,00 \\
\hline DBO - mg de $\mathrm{O}_{2} \cdot \mathrm{L}^{-1}$ & 1,50 \\
\hline Fenóis Totais - mg. $\mathrm{L}^{-1}$ & 0,90 \\
\hline
\end{tabular}

\subsection{Tratamento Biológico}

Foram feitas varreduras que acompanharam o desenvolvimento do tratamento biológico. Foram efetuadas três formas de tratamento biológico, sendo elas: a) com o uso do meio de cultura BGA; b) com o meio BGA (em que se substituiu a água destilada por efluente), também chamado de indutor em meio sólido e c) efluente autoclavado, tratado com fungo crescido em meio BGA. Na tentativa de aumentar a produção enzimática, principalmente fenoloxidases, efetuou-se a troca da água usada para a preparação do meio de cultura sólido pelo efluente puro. Como o efluente in natura continha fenol, que é um substrato dessas enzimas, viabilizou-se tal troca, pois compostos fenólicos são considerados agentes indutores sintéticos (Bollag e Leonowicz, 1984). Quando se usou o efluente no lugar da água no meio de cultura sólido, nas placas que continham Pycnoporus sanguineus, verificou-se a coloração amarronzada característica, indicando que a produção desta substância (cinabarina) está ligada à presença de compostos fenólicos, pois, em condições de meio de cultura BGA, não foi observada a síntese de tal composto.

As Figuras 2 mostram as varreduras nas três formas de tratamento biológico. Ao se observar a curva do efluente autoclavado tratado com os fungos (2c), conclui-se que a produção de PMS (Produtos
Microbianos Solúveis) e a degradação de compostos orgânicos, também são reguladas pela presença de outros microrganismos e não somente pela relação entre fonte de carbono e nitrogênio disponível para o fungo, como pode ser observado pelas menores absorbâncias apresentadas de 300 a $400 \mathrm{~nm}$, se comparado com o tratamento do efluente in natura.

Uma característica marcante observada é que no tratamento do efluente in natura (2A), tratado com fungos crescidos em meio BGA, o $P$. sanguineus em $24 \mathrm{~h}$ de tratamento, houve uma diminuição de absorbância em geral e que a partir desse tempo, a produção de PMS se faz mais presente, o que pode indicar que nesse primeiro período de $24 \mathrm{~h}$, o fungo utiliza as fontes orgânicas para sua manutenção e logo após esse período, a produção fúngica é voltada à produção de PMS. Diferentemente, o $S$. Comunne, nas mesmas condições que o P.sanguineus teve baixa produção de PMS, sendo mais pronunciado o consumo da matéria orgânica disponível.

O tratamento do efluente com os fungos crescidos em meio sólido com indutor, mostrou-se com maior produção de PMS, possivelmente já iniciado em placa. Ambos os fungos apresentaram as curvas com absorbância maior que a do efluente in natura, indicando que só houve produção de PMS, em todo o período de $96 \mathrm{~h}$ de tratamento. 


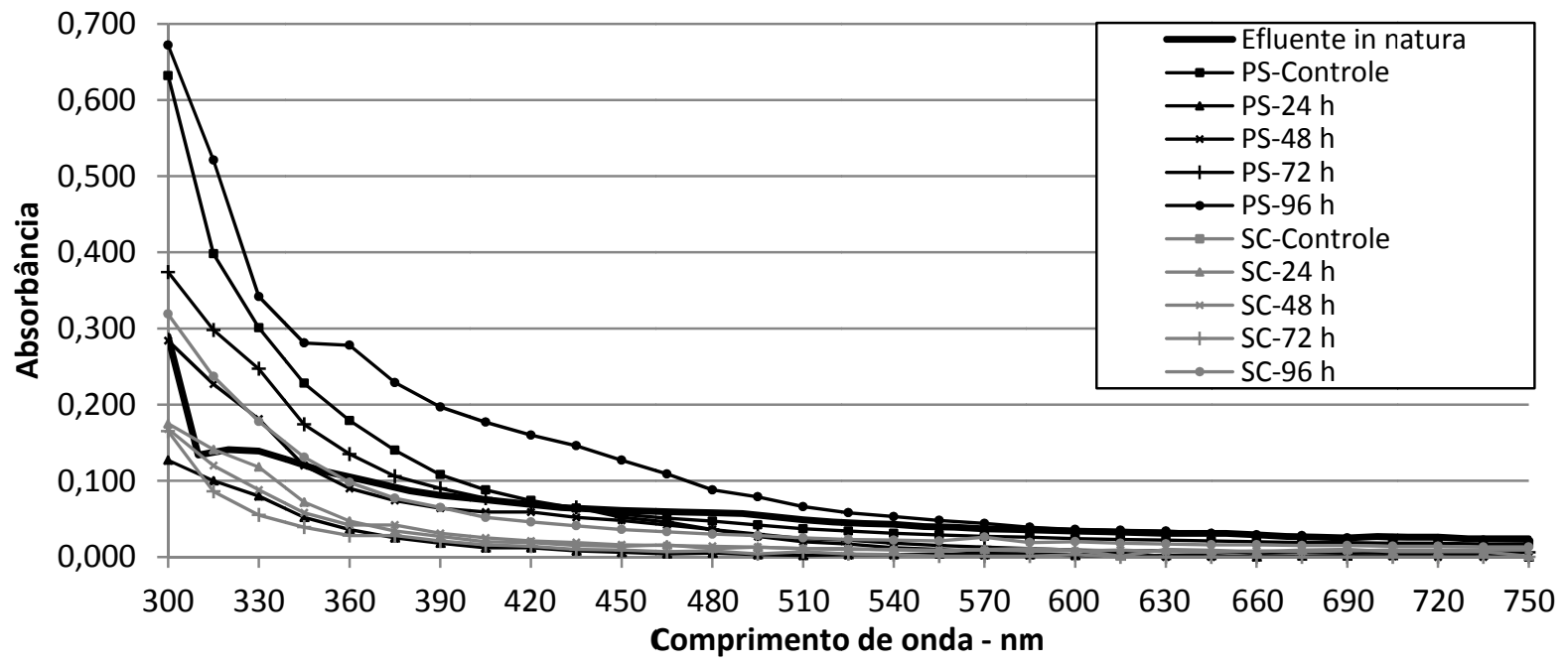

(2a)

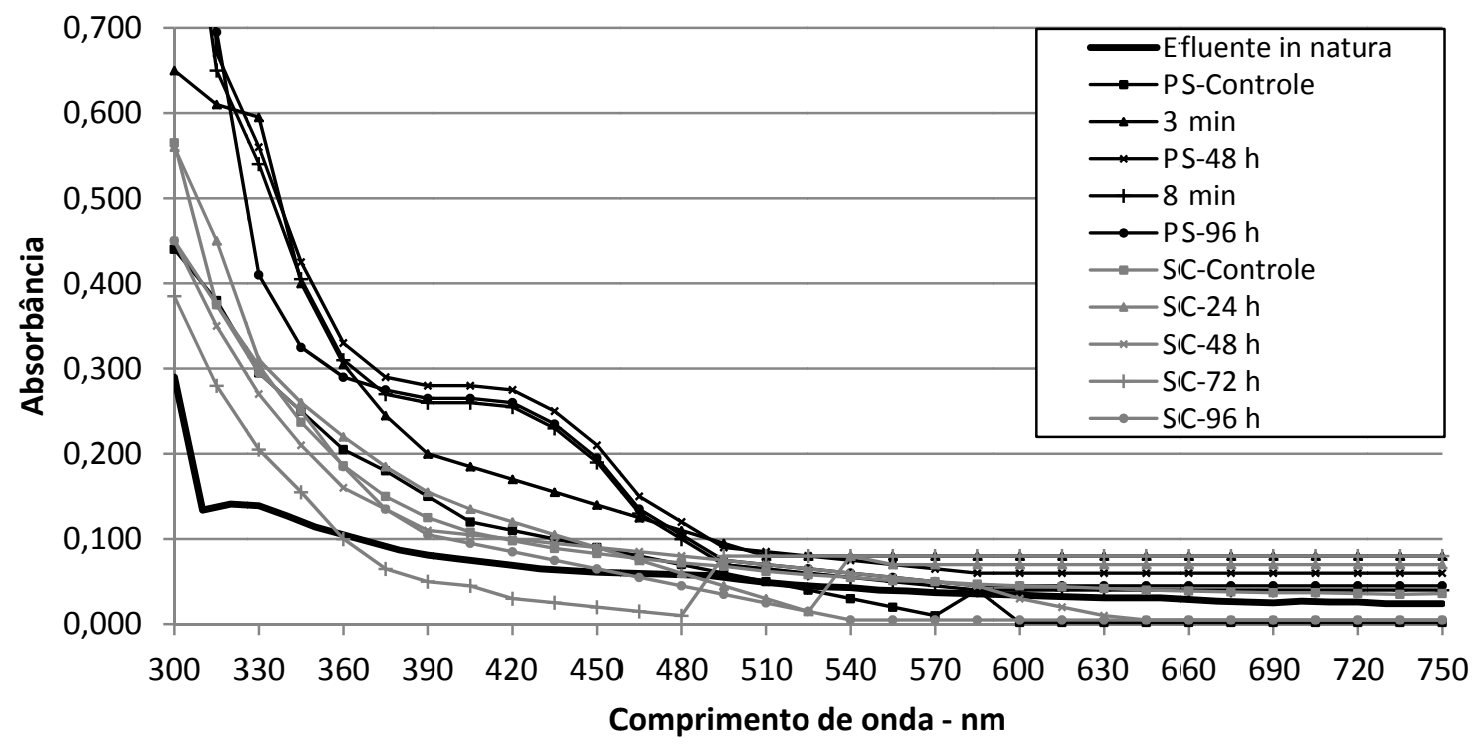

(2b)

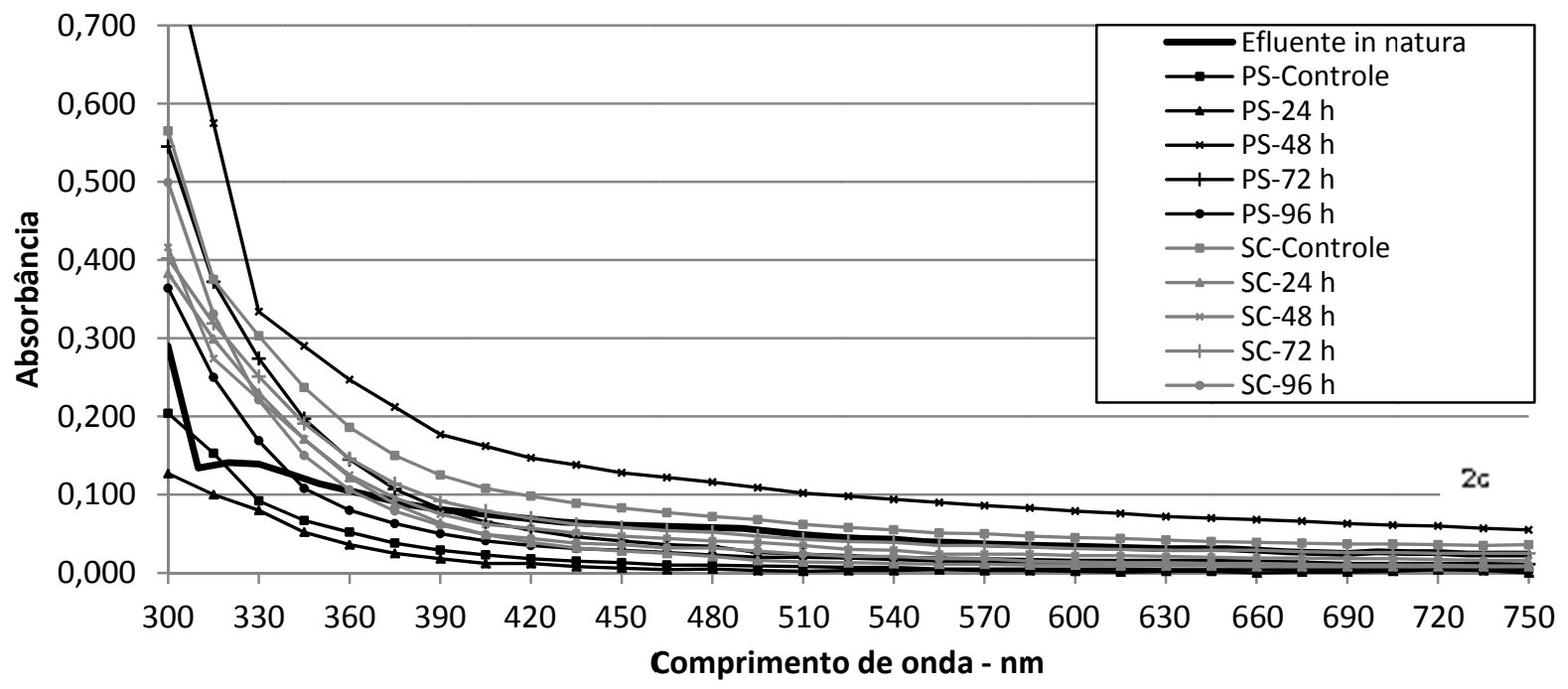

(2c)

Figura 2: Espectro de 300 a $750 \mathrm{~nm}$ do efluente tratado. O espectro do efluente in natura serve como comparação da modificação do efluente. 2a) Efluente tratado com fungo crescido em meio BGA. 2b) Efluente tratado com fungo crescido em meio com indutor sintético. 2c) Efluente autoclavado tratado com fungo crescido em meio BGA. 
A melhor performance da remoção da cor observada foi nas primeiras 72 horas de tratamento com o S. commune, o que pode ser explicado pela possível produção enzimática e não enzimática (sideróforos) ainda na placa de meio de cultura sólido, bem como durante tratamento biológico (Santiago, 1999). Outra possibilidade é indisponibilidade da manutenção do meio ideal de crescimento biológico (com o aproveitamento das fontes de carbono e nitrogênio do meio de cultura sólido e do efluente), pois ao se exaurir tais fontes, principalmente a fonte de carbono mais assimilável (glicose), o metabolismo fúngico seria prejudicado; diminuindo assim a produção de compostos fúngicos (Kamida et al., 2005).

As amostras tratadas com P.sanguineus apresentaram coloração amarronzada a partir de $72 \mathrm{~h}$ de tratamento, devido à cinabarina que é um antibiótico natural sintetizado por tal fungo (Smania et al., 1998) que apresentou alta solubilidade. De acordo com Garcia (2006), existe uma correlação da produção desse pigmento e a produção de lacase, embora a produção desse composto fosse detectada após 15 dias de crescimento em meio de cultura sólido, diferentemente do que foi determinado no tratamento do efluente da indústria farmacêutica. Em outro estudo (SMANIA et al., 1998), a síntese de tal composto só foi detectada depois de 18 dias de incubação.

Embora o S. comunne não tenha produzido lacase em nossos experimentos, a literatura científica mostra que ele pode produzir tal enzima (De Vriess et al., 1986). A melhor produção enzimática de lacase durante o tratamento com o fungo $P$. sanguineus foi quando se usou a indução em meio sólido (14,00 U. $\left.\mathrm{mL}^{-1}\right)$, conforme mostra a Figura 3. Quando não se usou a indução enzimática em meio sólido, para tratar o efluente, não houve produção de lacase, fato que pode ser explicado pela presença de outros microrganismos que inibiram a produção dessa enzima, enquanto o fungo produzia cinabarina, um antibiótico natural. Estudos mostram que as fenoloxidases se mostram muito ativas em $\mathrm{pH}$ ácido, contudo, altamente instáveis (Palmieri et al., 1993). Em nosso estudo, o $\mathrm{pH}$ apresentou variações, apresentando $\mathrm{pH}$ mais alto a partir de $72 \mathrm{~h}$ de tratamdo (Figura 4). Garcia (2006) demonstrou que Pycnoporus sanguineus tem maior produção quando se utiliza indutor e a presença de compostos fenólicos no efluente podem ter servido como indutores para a produção de lacase. Além disso, estudos mostram que o tipo de incubação (estático ou agitado) e a disponibilidade de fonte de nitrogênio orgânico é um importante incrementador da produção de lacase fúngica (Dong et al.,2005) o que também pode explicar a produção enzimática dos fungos estudados. Ao se usar o indutor em meio sólido (efluente in natura) verificou-se que tal procedimento inibe a produção de manganês peroxidase, possivelmente devido ao maior teor de matéria orgânica presente.

A maior variação de $\mathrm{pH}$ durante o tratamento com $P$. sanguineus, nas amostras tratadas com fungos com indutor no meio sólido e quando o efluente foi autoclavado, contudo, foi observado que em geral as amostras mantiveram $\mathrm{pH}$ entre 2,5 e 4,5, o que favorece a manutenção da viabilidade celular fúngica.
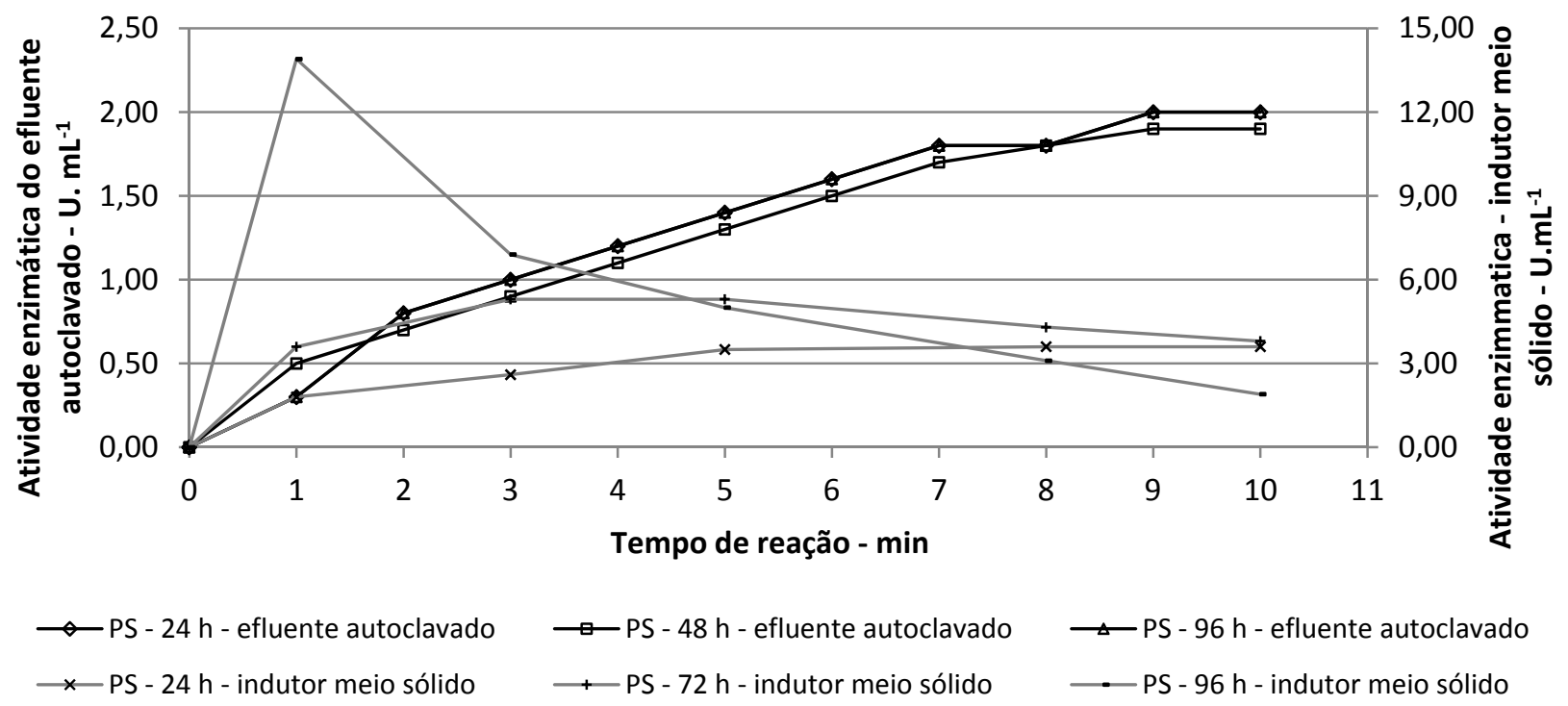

Figura 3: Determinação da atividade enzimática da lacase nos caldos filtrados da amostra em relação ao tempo de reação. 


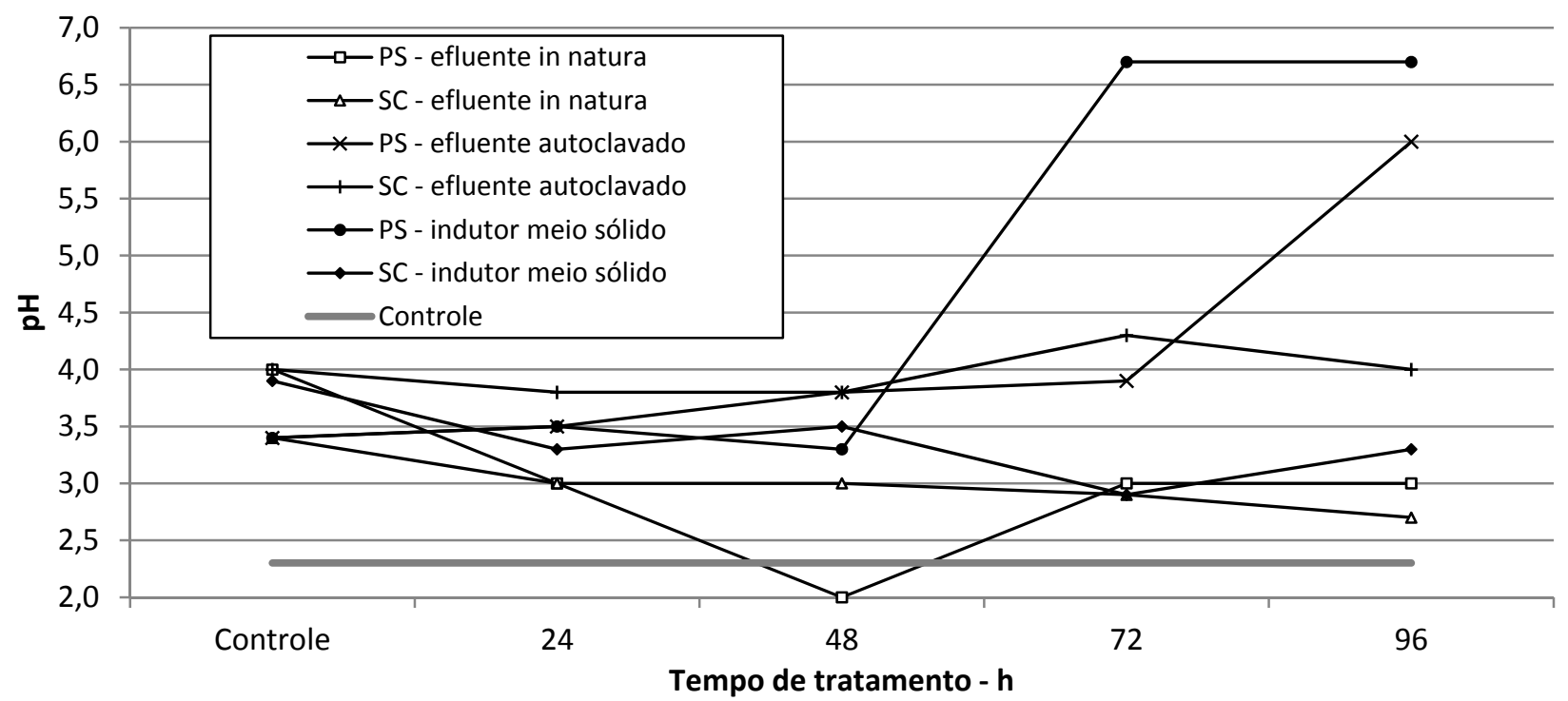

Figura 4-Variação do pH durante as três formas de tratamento biológico.

Diferentemente da lacase, indução em meio sólido não fez aumentar a produção de manganês, mas o tratamento do efluente usando os fungos crescidos em meio BGA foi o único que apresentou maior produção. $A$ Figura 6 mostra a concentração da enzima, após 5 min de oxidação do vermelho de fenol, nos diferentes tempos de tratamento. Estudos mostram que existe uma relação entre a atividade de manganês peroxidase e a concentração de peróxido de hidrogênio, sendo essa relação um fator limitante do processo enzimático. 0 oxigênio dissolvido (OD) também tem demonstrado que a reação do $\mathrm{Mn}^{3+}$ e $\mathrm{H}_{2} \mathrm{O}_{2}$ gera oxigênio que se acumula no caldo filtrado, atingindo valores de até $12,0 \mathrm{mg}$ de $\mathrm{O}_{2}$ $\mathrm{L}^{-1}$. Também foi constatado que em baixos níveis de oxigênio dissolvido, a enzima apresentou maior atividade, possivelmente devido à relação ideal entre o peróxido e a enzima (López et al., 2004). Tal constatação pôde ser comprovada pela baixa concentração de OD do efluente $\left(3,10 \mathrm{mg}\right.$ de $\left.\mathrm{O}_{2} \cdot \mathrm{L}^{-1}\right)$.

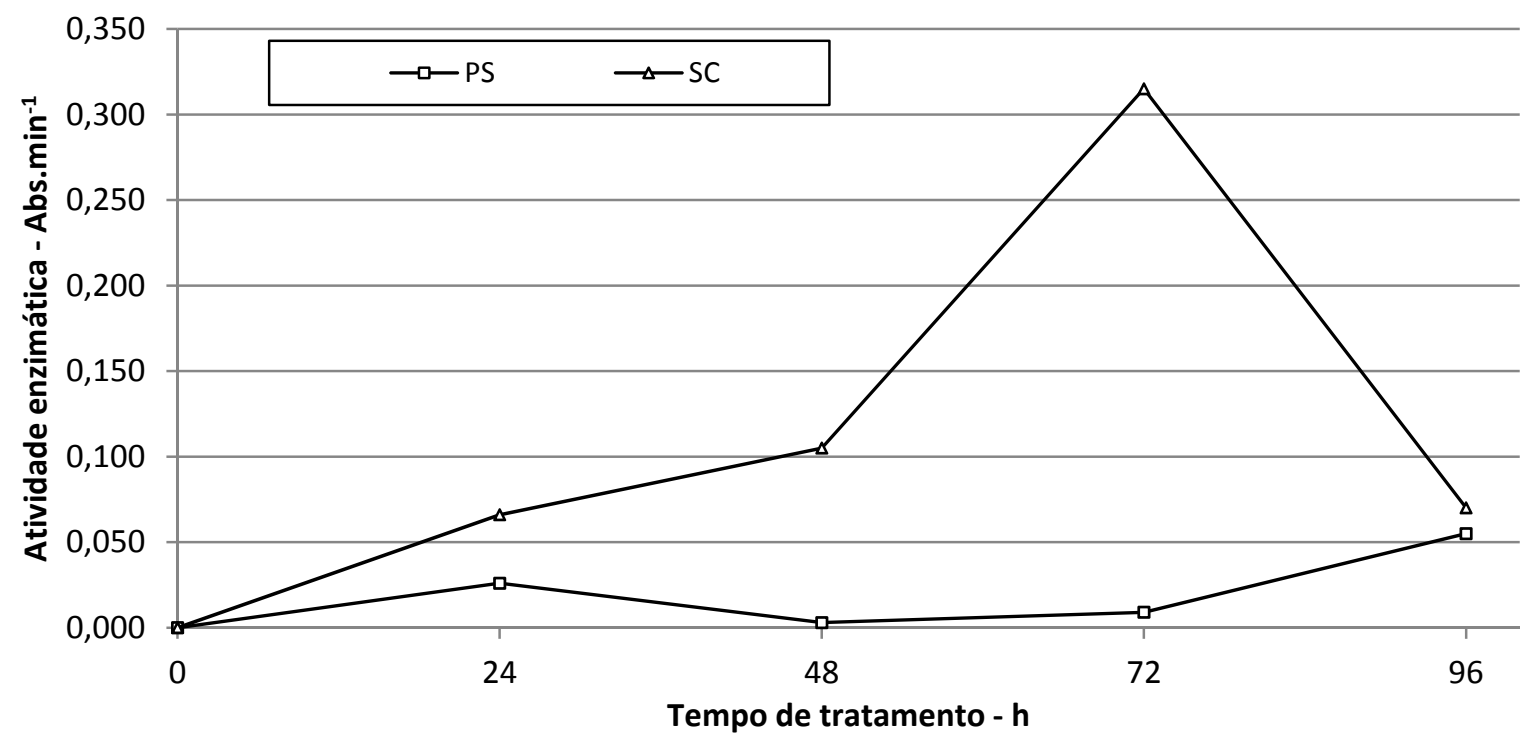

Figura 5: Determinação da atividade de manganês peroxidase dos caldos filtrados do efluente tratado, com fungo crescido em meio BGA, após 5 min de incubação a $30 \circ \mathrm{C}$ em pH 4,5 e vermelho de fenol como substrato. 
Para se avaliar o decaimento da matéria orgânica presente no efluente tratado, foi avaliado a DQO (solúvel, pois os caldos eram filtrados em membrana 0,45 $\mu \mathrm{m}$ ), conforme a Figura 6. Por se tratar de um sistema heterogêneo, em que se diferencia a fase sólida (micélio, agar e particulados) da fase líquida (solúvel), a bioatividade fúngica (variação de $\mathrm{pH}$, síntese enzimática, etc.) pôde ir modificando a proporção entre as duas fases, levando a resultados em que a relação de DQO seja superior a 1,00. Entretanto, valores abaixo de 1,00 (degradação), não podem ser interpretados como redução da matéria orgânica presente no efluente tratado, pois tal metodologia avalia toda matéria orgânica contida na amostra, sendo que os Produtos Microbianos Solúveis estavam presentes no meio, impossibilitando a interpretação dos resultados.

A maior diminuição da DQO (Figura 6) observada nas formas de tratamento biológico foi quando se usou o $S$. comunne após $48 \mathrm{~h}$ de tratamento (93\%) e o efluente tratado pelo mesmo fungo, com indução em meio sólido (78\%). A presença de microrganismos no efluente mostrou-se positivo para o tratamento fúngico, diferentemente do que foi observado quando se utilizou-se o efluente autoclavado, que apresentou maior produção de produtos microbianos solúveis, o que inviabilizou a observação da diminuição da matéria orgânica no meio reacional. Para o P. sanguineus, pôde-se relacionar a indução em meio sólido com a produção de lacase $\left(14,00 \mathrm{U} \mathrm{mL}^{-1}\right)$ e a degradação da matéria orgânica $(61 \%$ em 96 h de tratamento). Contrariamente, tal correlação não pode ser aplicada para o S. Comunne.

A troca da água destilada pelo efluente contendo fenol para a preparação do meio de cultura em meio sólido teve pouco impacto no crescimento micelial ( 5 dias) do fungo Schizophyllum commune, difererentemente do observado co $P$. sanguineus, que apresentou $100 \%$ de proliferação da placa de Petri, mas com maior formação de biomassa. A Figura 7 demonstra a relação do crescimento micelial dos fungos que foram afetados pela substituição do meio de cultura sólido. Cabe salientar que o $P$. sanguineus não apresentou a produção de cinabarina, quando se usou o indutor em meio sólido.

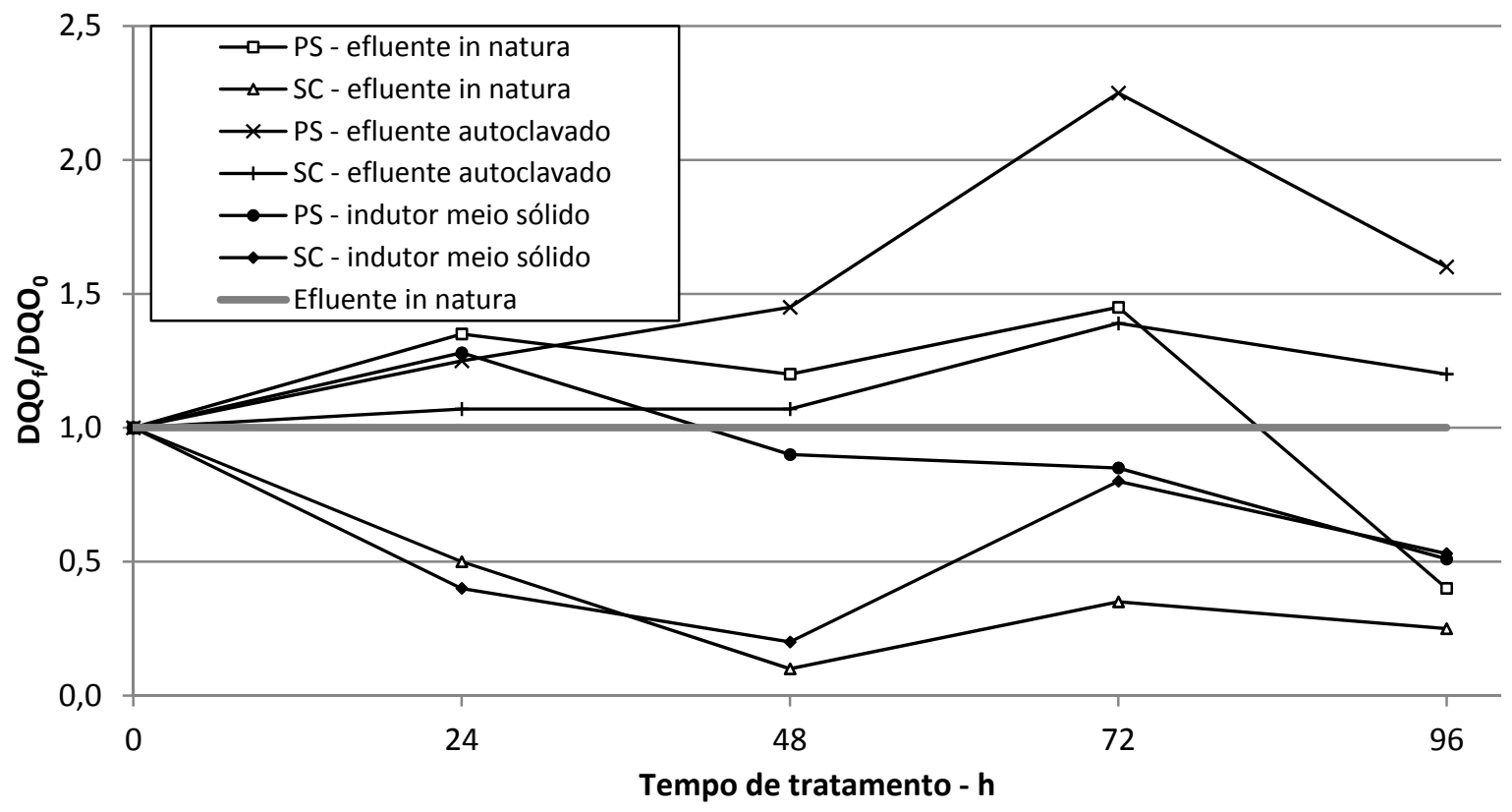

Figura 6: Variação da DQO durante o tratamento biológico.

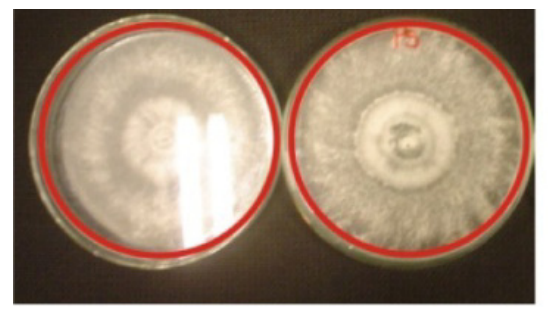

PS

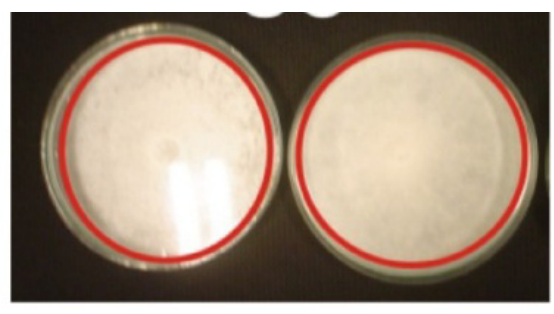

b

SC

Figura 7: Fotos comparativas dos meios sólidos, utilizando-se o meio BGA (a) e meio com adição de indutor sintético (b). 


\subsection{Processo Combinado de Biorremediação seguido de} Fotocatálise

O processo combinado, com o tratamento biológico seguido do tratamento fotocatalítico com catalisador disperso apresentou baixo rendimento, pois ao se adicionar o catalisador, havia uma adsorção do catalisador com os biocompostos fúngicos, o que inviabilizou o processo de oxidação dos contaminantes orgânicos. Estudos mostram que a adsorção da matriz orgânica e inorgânica presente no efluente leva formação de espécies complexas com o catalisador (" $\mathrm{TiOH}_{2}{ }^{+}-\mathrm{Cl}$-“" Wizniowski et al., 2004), diminuindo a eficiência do processo de degradação. De acordo com Ziolli e Jardim (1998), compostos hidrofílicos tendem a serem adsorvidos pelo catalisador e como os PMS são hidrofílicos, assim como o catalisador, tal comportamento impede que a superfície de reação tenha sua eficiência no processo de fotodegradação. As Figuras 8 e 9 mostram a distribuição de massas, analisadas por espectrômetro de massa.

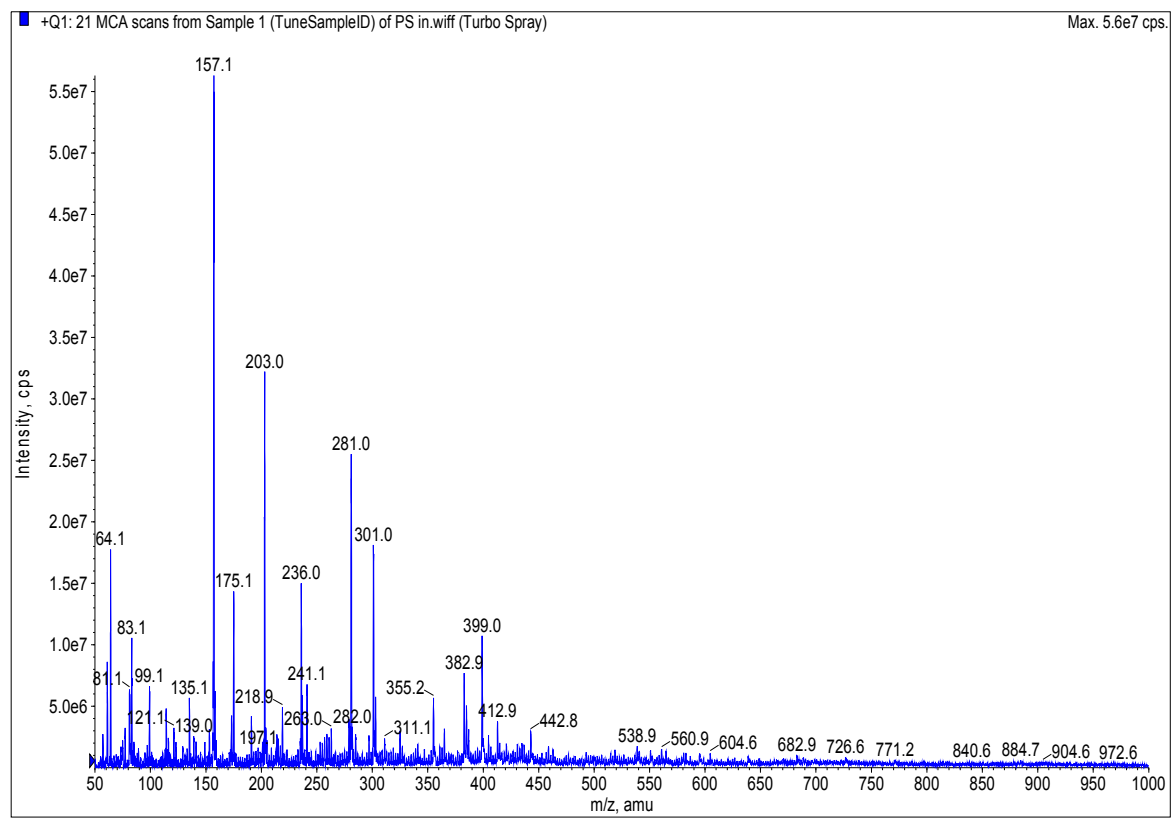

(a)

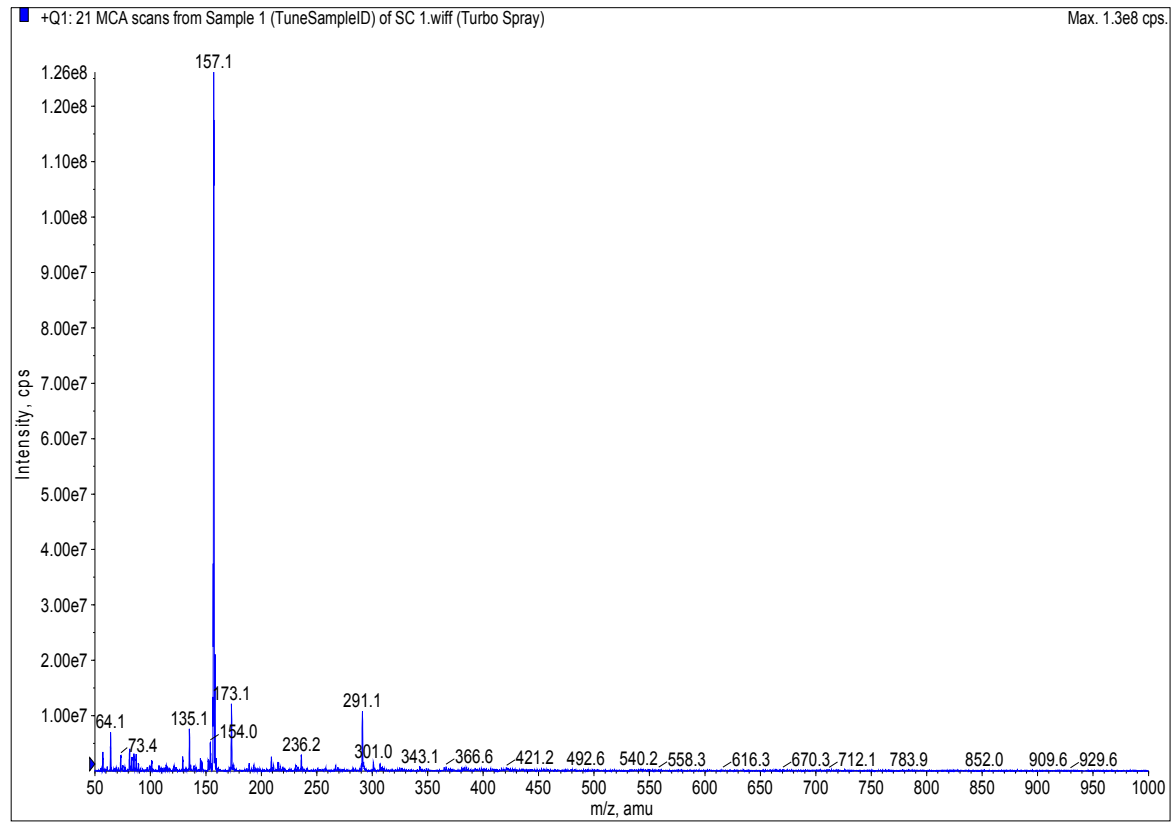

(b)

Figura 8: Espectro de massa do efluente tratado, em modo positivo, com relação m/z entre 50 e 1000 Da.

(a) P. sanguineus (b) S. comunne. 


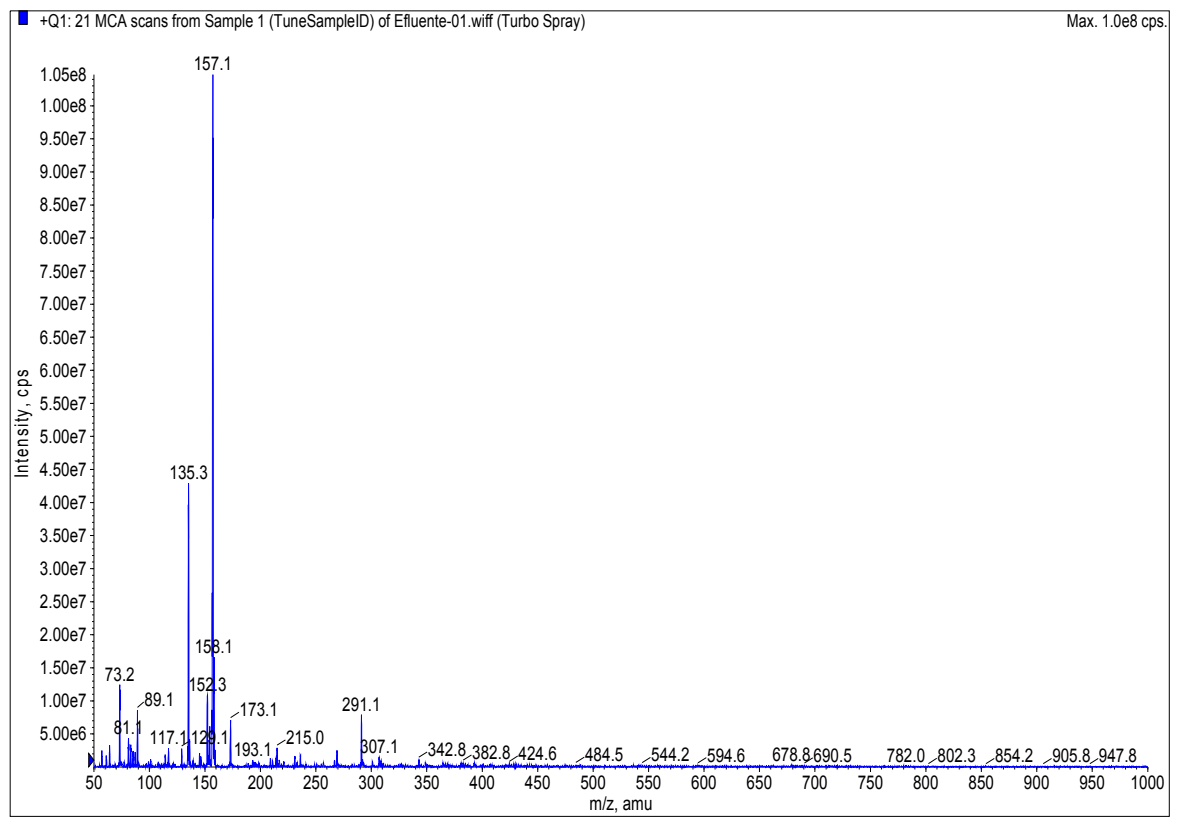

(c)

Figura 9: Espectro de massa do efluente tratado, em modo positivo, com relação m/z entre 50 e 1000 Da.

(c) Efluente não tratado.

Observando-se as Figuras 8 e 9, nota-se um aumento na distribuição de massas, comparando-se com o efluente não tratado. Tal aumento é proporcional ao aumento de PMS, que inviabilizara o tratamento fotocatalítico após o tratamento com fungos.

A Figura 10 mostra a evolução do tratamento fotocatalítico inicialmente tratado por Pycnoporus sanguineus. Observando-se as curvas, constatou-se um aumento da coloração em $400 \mathrm{~nm}$, sendo que em 16 min de tratamento, houve redução de apenas $10 \%$ da DQO, o que mostra que o processo catalítico como processo de pós tratamento por fungos, não apresentou viabilidade de um pré-tratamento biológico. Para o fungo $S$. comunne, os PMS's tiveram importância marcante para a inviabilidade do processo fotocatalítico com catalisador disperso, o que fez com que não houvesse degradação nem mudança da curva de varredura.

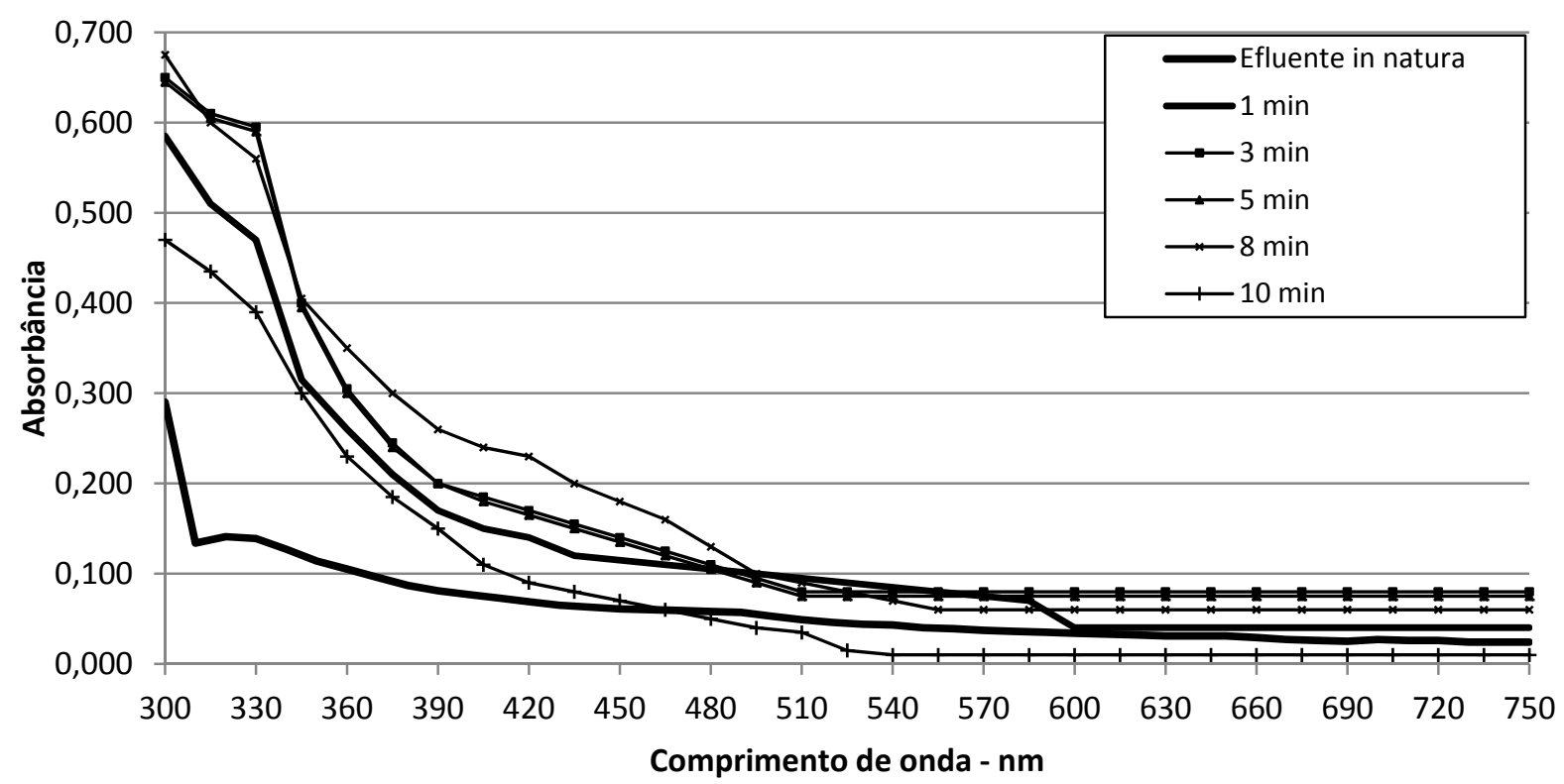

Figura 10: Espectro de 300 a $750 \mathrm{~nm}$ da amostra tratada com $P$. sanguineus em $96 \mathrm{~h}$ de tratamento, com posterior tratamento fotocatalítico. 


\subsection{PROCESSO COMBINADO DE FOTOCATÁLISE SEGUIDA DE BIORREMEDIAÇÃO}

A segunda parte do tratamento combinado foi realizada utilizando-se 0 efluente tratado fotocataliticamente por $8 \mathrm{~min}$. Escolheu-se esse tempo de tratamento, pois a degradação do fenol foi de $50 \%$ neste período, sendo que o fenol residual pode ser um indutor para a produção de lacase, o que pode vir a melhorar o processo de degradação de compostos orgânicos. O tratamento com os fungos foi monitorado espectrofotometricamente, de acordo com a Figura 10. Para efeito de comparação, foi inserida a curva do efluente in natura e do efluente tratado fotocataliticamente em oito min. Devido ao bom desempenho na produção de lacase, quando do tratamento biológico, o tratamento do efluente fotocataliticamente tratado foi com fungo crescido em meio BGA com indutor (efluente).

Nas primeiras $24 \mathrm{~h}$ de tratamento, o caldo filtrado apresentou redução de absorbância, verificado em todos os fungos. A partir de $72 \mathrm{~h}$ de tratamento, houve um aumento da absorbância, caso já citado por Aquino (2003), em que o tempo de tratamento se relaciona com o aumento da coloração do efluente tratado e aumento de PMS. O P. sanguineus apresentou maior coloração relacionada à cinabarina, a partir de $48 \mathrm{~h}$ de tratamento, caso similar às outras formas de tratamento não combinada. Observar que a partir de $72 \mathrm{~h}$ de tratamento com o $P$. sanguineus, não houve modificação do espectro, sendo que em $400 \mathrm{~nm}$, houve um aumento significativo em relação ao efluente in natura e o efluente previamente tratado. Para o $S$. comunne, em $72 \mathrm{~h}$ de tratamento, ocorreu uma diminuição da coloração, tanto em relação do efluente in natura, quanto do efluente fotocatalitimente tratado, mas em 96 h de tratamento, a coloração do efluente foi maior que o efluente in natura, indicando que para a diminuição de cor, o ideal é usar o $S$. comunne durante $72 \mathrm{~h}$ de tratamento.

A atividade da lacase foi acompanhada conforme mostra a Figura 11, mas o comportamento das curvas apresenta que o fungo Pycnoporus sanguineus em $96 \mathrm{~h}$ de tratamento apresentou maior atividade enzimática em $3 \mathrm{~min}$ de reação $\left(13,90\right.$ U. $\left.\mathrm{mL}^{-1}\right)$. Novamente, o S. comunne não apresentou síntese de tal enzima. A variação do $\mathrm{pH}$ dos caldos filtrados foi monitorada como mostra a Figura 12, sendo que o intervalo diminuiu entre o valor máximo e mínimo alcançado durante o tratamento, significando que compostos fúngicos foram produzidos em menor quantidade, o que também pôde ser comprovado pela Figura 13. Nessa forma de tratamento combinado, o pH continuou ácido, sendo o valor mais alto monitorado de $4,1$.

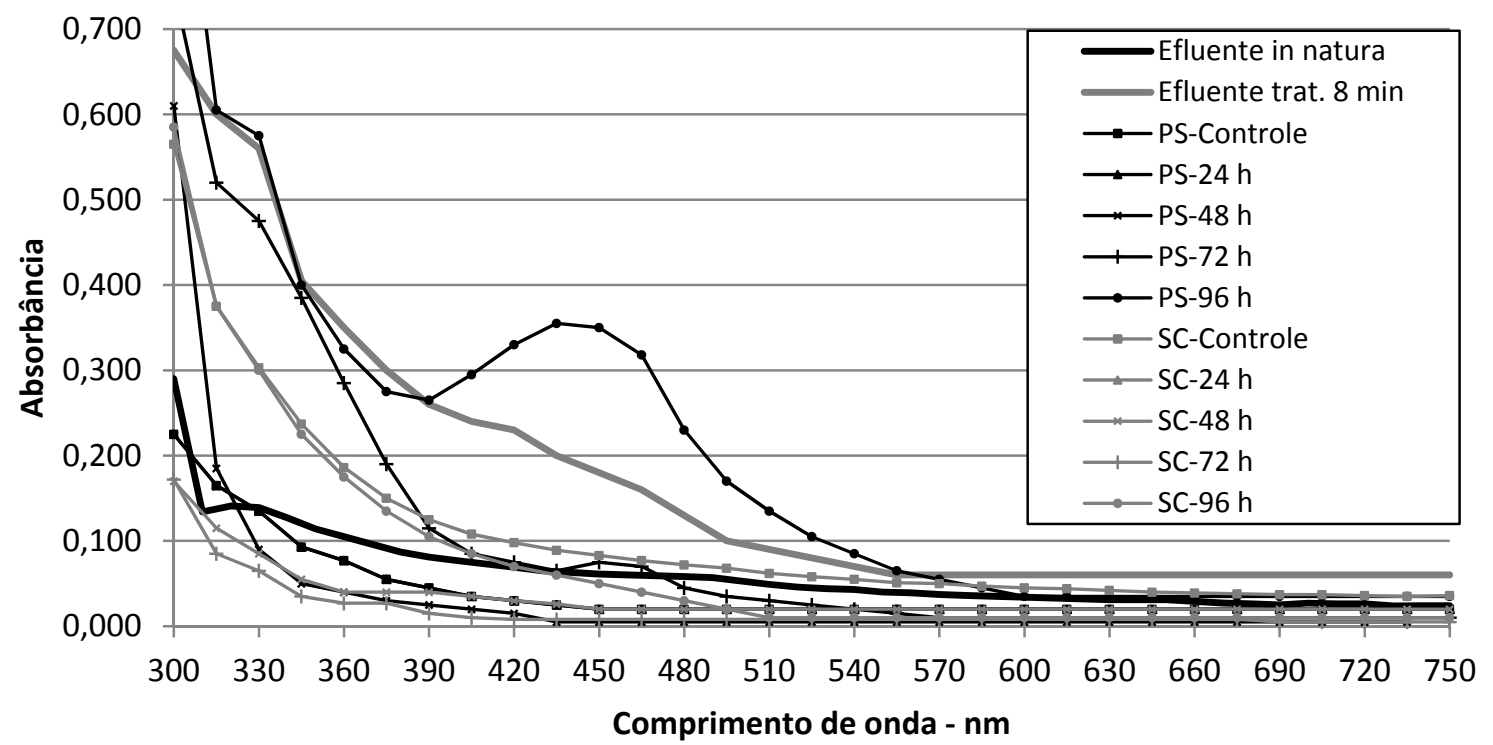

Figura 11: Absorbância do intervalo de 300 a $750 \mathrm{~nm}$ da amostra previamente tratada por processo fotocatalítico, durante oito min. 0 espectro do efluente in natura e do tratado fotocaliticamente serve como comparação da modificação do efluente. 


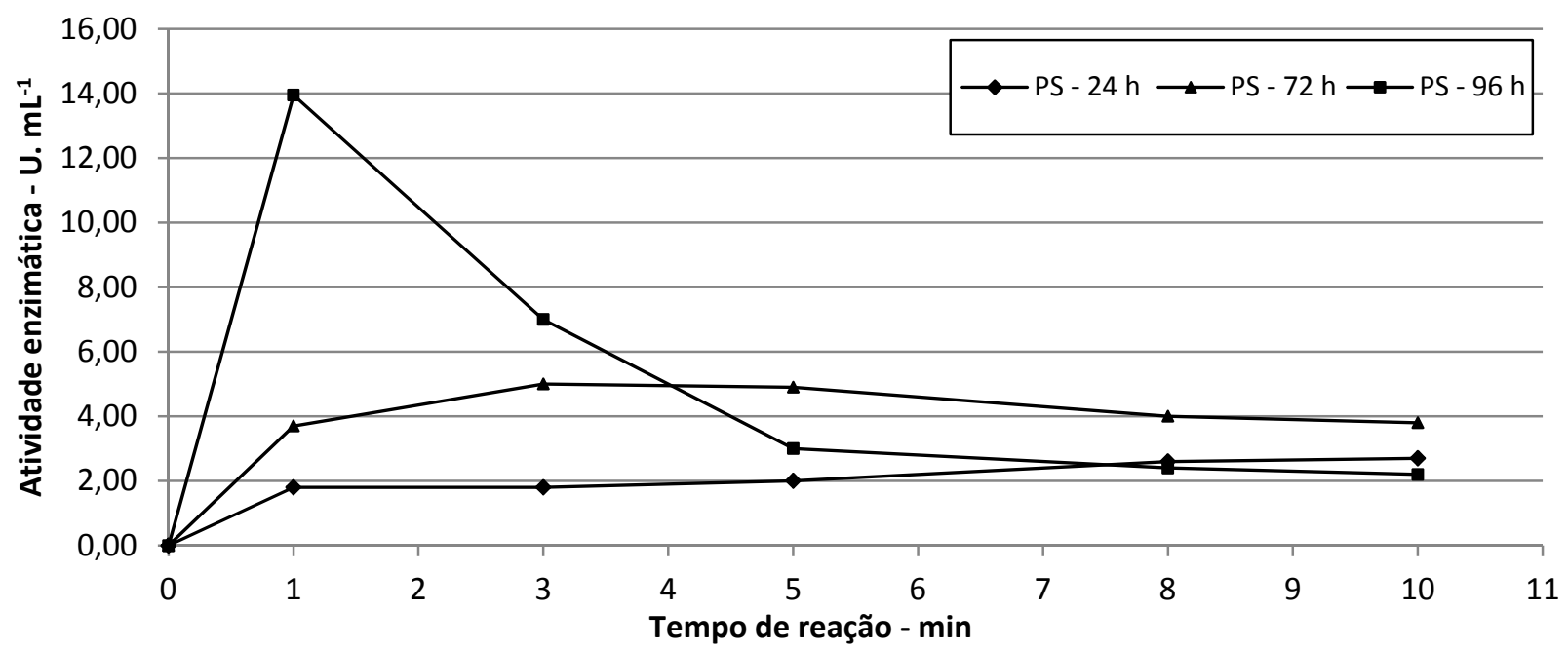

Figura 12: Variação da atividade enzimática da lacase nos caldos filtrados, usando-se indutor em meio sólido, em relação ao tempo de reação.

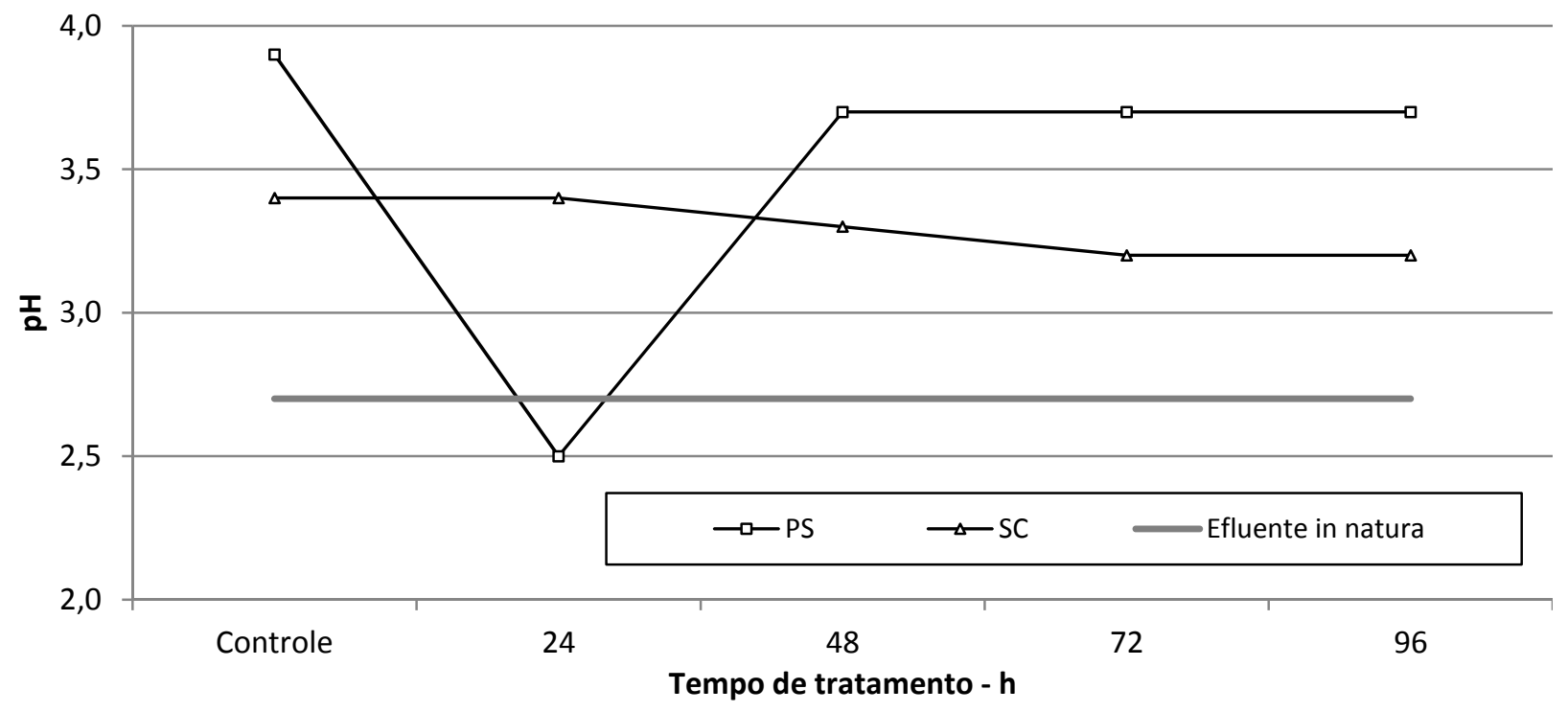

Figura 13: Variação do $\mathrm{pH}$ durante o tratamento do efluente pré-tratado fotocataliticamente, durante 8 min.

Diferentemente do efluente tratado biologicamente, a produção de manganês-peroxidase não foi expressiva (50 vezes menor que no tratamento fúngico). Uma das possíveis causas foi o aumento da toxicidade do efluente fotocataliticamente tratado em 8 min (dado não mostrado). Além disso, em 8 min de tratamento, a DQO reduziu apenas $5 \%$, o que pode ter produzido moléculas mais tóxicas, conforme já comprovado pelo teste da toxicidade. A Figura 14 mostra a produção de Manganês-peroxidase, durante o tratamento combinado. Outra característica apresentada foi que o $S$. comunne não produziu manganêsperoxidase, o que também pode ser explicado pela diminuição de manganês disponível no efluente pré tratado $\left(0,50 \mathrm{mg} \mathrm{L}^{-1}\right)$.

O decaimento da DQO mostrou que o fungo $S$. comunne apresentou a degradação de $90 \%$ em 72 h de tratamento da matéria orgânica, demonstrando que esse fungo possui um sistema de degradação que não envolve as enzimas Manganês-peroxidase, Lignina peroxidase e lacase. Entretanto, mesmo o $P$. sanguineus também apresenta degradação da matéria orgânica de $90 \%$ em $96 \mathrm{~h}$ de tratamento, mesmo com a mesma quantidade de lacase detectada no tratamento biológico, portanto, para o $P$. sanguineus, a síntese de lacase e Manganêsperoxidase não está relacionada com a degradação da matéria orgânica. A Figura 15 mostra a relação de DQO, quando se usou o efluente contendo fenol como meio de indução enzimática, para um efluente pré-tratado fotocataliticamente. Para melhor avaliação do potencial de degradação do método biológico proposto, o estudo de contaminantes específicos da indústria farmacêutica deve ser usado, como a cromatografia líquida, acoplada a espectrômetro de massa (Aquino, 2003). 


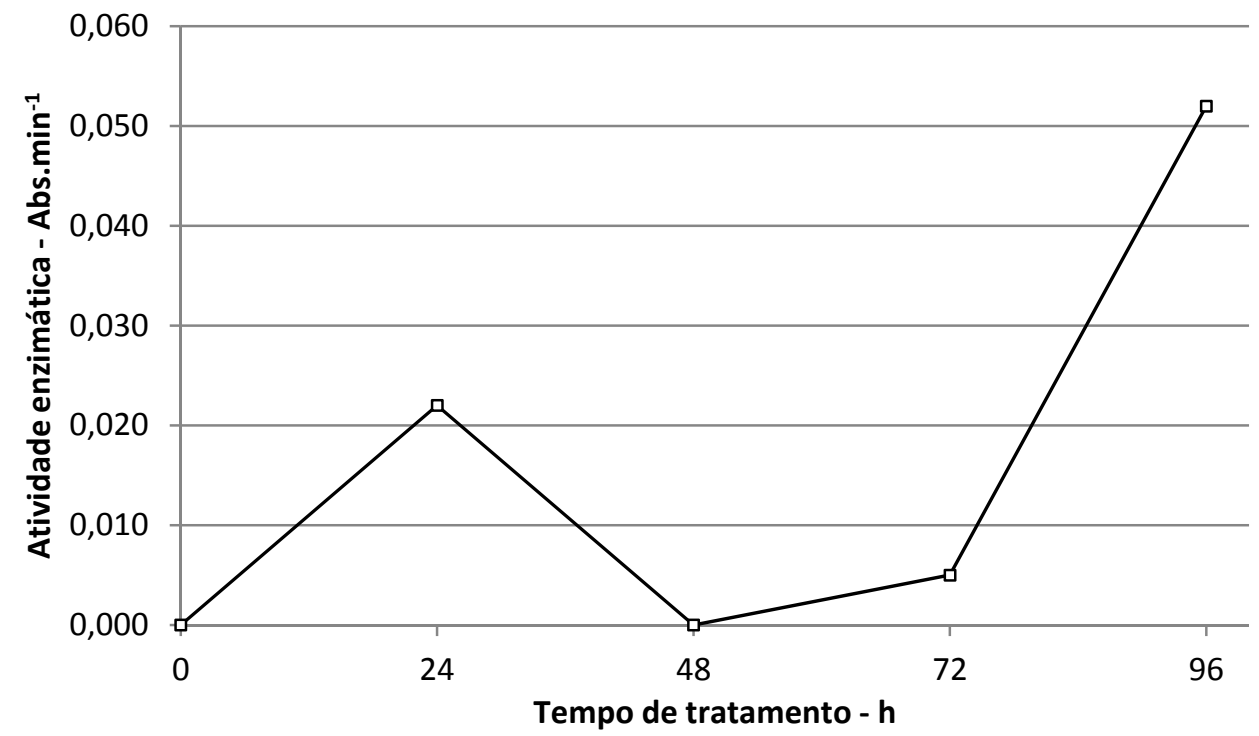

Figura 14: Variação da produção de Manganês-peroxidase, com efluente pré tratado fotocataliticamente (8 min).

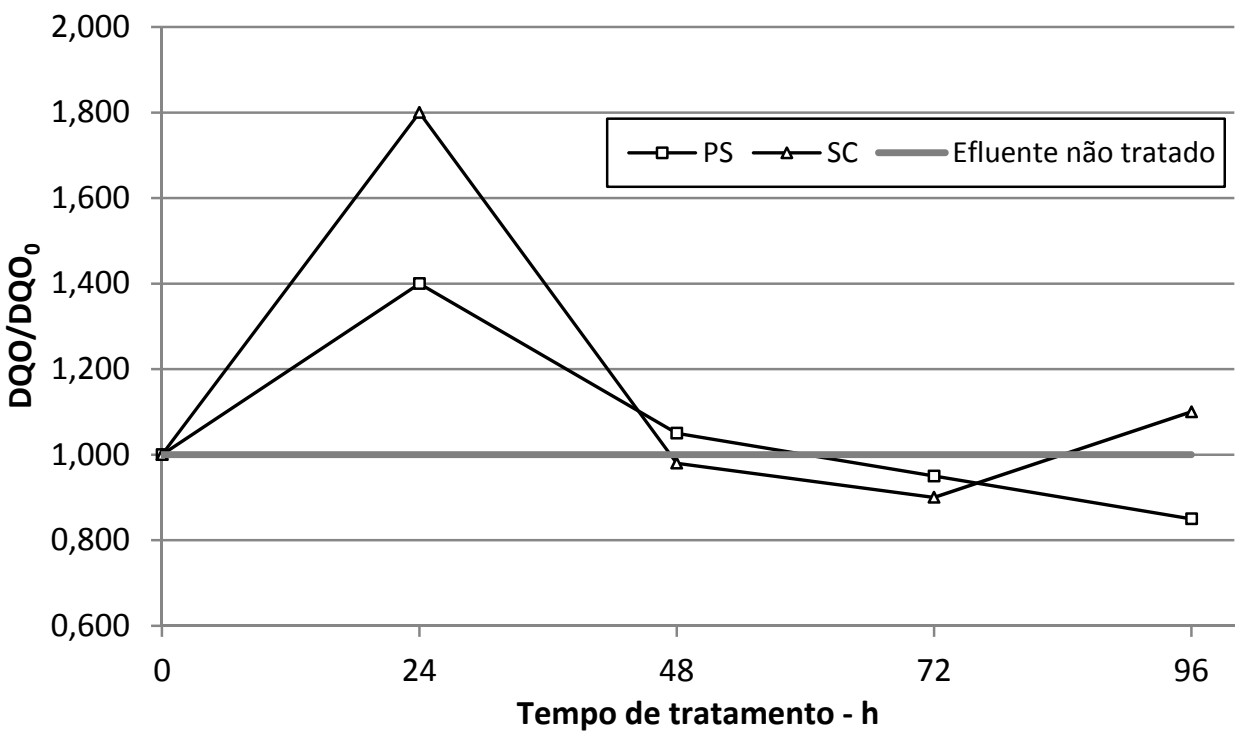

Figura 15: Relação entre a DQO final e a DQO inicial da amostra. A linha mais escura indica o que abaixo dela, observa-se a degradação da matéria orgânica do efluente in natura.

Para efeito de comparação dos resultados de toxicidade para Artemia salina, compararam-se os resultados do tratamento biológico e do tratamento combinado (Figura 16). Para o fungo $P$. sanguineus, a maior diminuição da taxa de mortalidade foi usando-se o tratamento biológico, com o efluente autoclavado. De acordo com os dados, a produção de cinabarina pelo fungo é o maior responsável pela toxicidade do efluente tratado. Inversamente, o efluente tratado biologicamente com fungo $S$. comunne crescido em meio BGA teve a menor taxa de mortalidade, sendo que o tratamento combinado apresentou a maior taxa de mortalidade, o que pode estar relacionado com a diminuição do nível de nitrogênio no meio, aumentando o stress metabólico do fungo.

Não foi possível determinar a atividade de Lignina peroxidase durante o tratamento e nem mesmo houve produção desta enzima no meio de cultura sólido. Em nenhuma forma de tratamento foi detectada essa enzima, o que pode ser explicado pela falta de um indutor (lignina) ou mesmo a baixa concentração de oxigênio presente no efluente original Belinky et al. (2003) associa a concentração de oxigênio à síntese de Lignina peroxidase, o que nos leva a crer que o oxigênio dissolvido foi um importante fator inibitório para a síntese de tal enzima. 


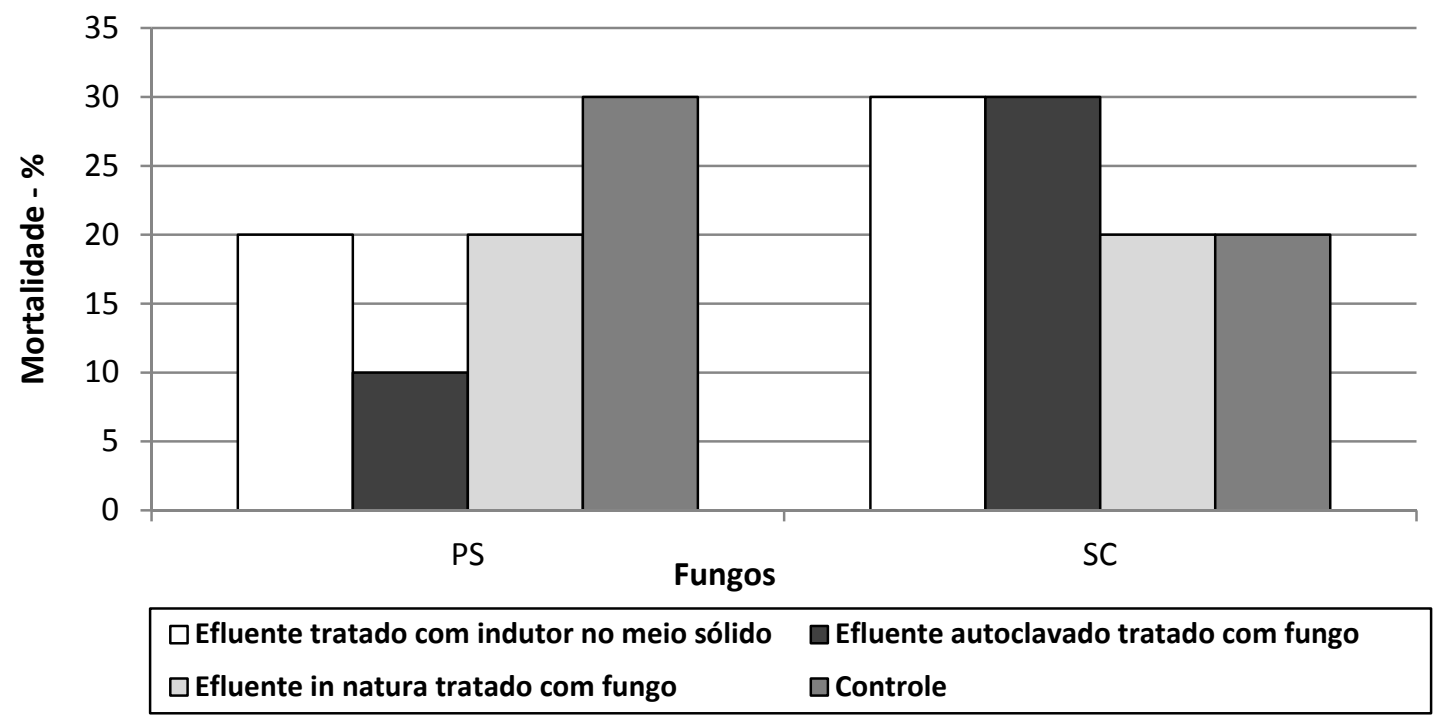

Figura 16: Mortalidade dos náuplius de Artemia salina, nas diferentes formas de tratamento.

Não foi possível determinar a atividade de Lignina peroxidase durante o tratamento e nem mesmo houve produção desta enzima no meio de cultura sólido. Em nenhuma forma de tratamento foi detectada essa enzima, o que pode ser explicado pela falta de um indutor (lignina) ou mesmo a baixa concentração de oxigênio presente no efluente original Belinky et al. (2003) associa a concentração de oxigênio à síntese de Lignina peroxidase, o que nos leva a crer que o oxigênio dissolvido foi um importante fator inibitório para a síntese de tal enzima.

\section{CONCLUSÃO}

O melhor resultado para diminuição da matéria orgânica (DQO) foi o tratamento biológico como fungo $S$. comunne, crescido em meio BGA com indutor sintético. Além disso, o método de avaliação de DQO não se mostrou específico, devido à interferência dos meios de cultura adicionados ao sistema, fazendo-se necessário o uso de um método mais restritivo para identificação e quantificação de um grupo de moléculas presentes no efluente da indústria farmacêutica. A partir dos resultados apresentados, o tratamento biológico com fungos apresentou melhores resultados na diminuição da DQO que o método combinado com fotocatálise, o que pode ser explicado pela heterogeneidade do efluente coletado, pois a indução da produção de PMS tem papel importante na eficiência dos métodos combinados com fotocatálise.

\section{AGRADECIMENTOS}

Este trabalho foi financiado por International Foundation for Science (IFS)/W3433-1, CNPQ (Conselho Nacional de Pesquisa), SECTEC-GO (Secretaria Ciência e Tecnologia do Estado de Goiás) e Edital MCT/CNPq/CTHidro no 14/2005.

\section{REFERÊNCIAS}

APHA, AWWA and WPCF Standard Methods for the Examination of Water and Wastewater, Eaton, A.D; Clesceri, L. S., Greenberg, A. E. (Eds.). $19^{\text {th }}$ Edition American Public Health Association, 1995.

AQUINO, S. F. Caracterização Da DQO Efluente De Sistemas De Tratamento Biológico. Engenharia Sanitária e Ambiental, 8, 3, 135-144, 2003.

ASSALIN, M. R.; FIGUEIREDO, R. F.; ZIOLLI, R. L.; GUIMARÃES, J. R. Processos Oxidativos Avançados (POA): aplicação da fotocatálise heterogênea na desinfecção de águas de abastecimento. XXVII Congresso Interamericano de Engenharia Sanitária e Ambiental ,1999.

BARR, D. P.; AUST, S. D. Mechanisms white rot fungi use to degrade pollutants. Environmental Science e Technology, 28(2), 79A-87A, 1994.

BELINKY, P. A.; FLIKSHTEIN, N.; LECHENKO, S.; GEPSTEIN, S.; DOSORETZ, C. G. Reactive Oxygen Species and Induction of Lignin Peroxidase in Phanerochaete chrysosporium Applied Environmental Microbiology, 69, 11, 6500-6506, 2003.

BOLLAG, J-M; LEONOWICZ, A. Comparite Studies of Extracelullar Fungal Laccases. Apllied Environmental Microbiology, 48, 849-854, 1984.

CARDOSO, L; LUCA, S. J. Toxicity of Biologically Treated Efffluents Disinfected By Hypochlorite And Ferrate (VI). Engenharia Sanitária E Ambiental, 9, 1, 26-29, 2004. 
CAVALCANTE, M. F.; OLIVEIRA, M. C. C. DE; VELANDIA, J. R.; ECHEVARRIA A. Síntese De 1,3,5-Triazinas Substituídas e Avaliação da Toxicidade Frente a Artemia salina Leach, Química Nova, 23, 1, 20-22, 2000.

CORDEIRO, A. C. S.; LEITE, S. G. F.; DEZOTTI; M. Inativação Por Oxidação Fotocatalítica De Escherichia coli E Pseudomonas sp. Química Nova, 27, 5, 689-694, 2004.

CORREIA, C. R. D. , COSTA, P. R. R., FERREIRA, V. F. Vinte e cinco anos de reações e estratégias em química orgânica. Química Nova, 25, 74-80, 2002.

COSTA, F. C.; CAMPOS, J. C.; SANT'ANNA JR, G. L.; DEZOTTI, M. Aplicação De Carvão Ativado Em Pó (CAP) Ao Processo Biológico De Tratamento De Um Efluente Da Indústria Química. Revista de Engenharia Sanitária e Ambiental, 9, 2, 170-176, 2003.

DANTAS, T. L. P., JOSÉ, H. J., MOREIRA, R. DE F. P. M. Fenton and Photo-Fenton oxidation of tannery wastewater. Acta Scientiarum - Technology, 25, 1, 91-95, 2003.

DAUGHTON, C. G.; TERNES, T. A. Pharmaceuticals and personal care products in the environment: Agents of subtle change? Environmental Health Perspectives, 107, 907-938, 1999.

DE VRIES, O. M. H.; KOOISTRA, W. H. C. F.; WESSELS, G. H. Formation of An Extracellular Laccase By Schizophyllum Commune Dikaryon. Journal of Genetic of Microbiology 132, 2817-2836,1986.

DONG, J. L.; ZHANG, W.; ZHANG, R.; HUAI, H.; WEI, Z. Influence of Culture Condition on Laccase Production and Isoenzyme Patterns in the White-rot Fungus Trametes gallica. Journal of Basic Microbiology, 45, 3, 190-198, 2005.

FERREIRA, I. V. L.; DANIEL, L. A. Fotocatálise Heterogênea com TiO2 aplicada ao tratamento de esgoto sanitário secundário, Engenharia Sanitária e Ambiental 9(4): 335-342, 2004.

FILIPIC, M.; TOMAN ,M.J. Ecotoxicological studies using modified Ames bioassay. Water ScienceTechnology, 34: 1-7, 1996.

FREIRE R. S., PELEGRINI R., KUBOTA L. T.; DURÁN, N.; PERALTAZAMORA, P. N. Novas tendências para o tratamento de resíduos industriais contendo espécies organocloradas, Química. Nova,23 , 4, 504-511, 2000.

FU, Y.; VIRARAGHAVAN, T. Fungal decolorization of dye wastewaters: a review. Bioresource technology; 79: 251-262, 2001.

GARCIA, T. A. Produção e caracterização de duas lacases do Fungo Pycnoporus sanguineus, Tese de doutorado, Universidade de Brasília, 2006.

HALLING-SORENSEN, B. et al. Occurence, fate and effects of pharmaceutical substance in the environment - a review. Chemosphere; 36, 2, 357-393, 1998.

$\mathrm{HE}, \mathrm{C}$; ; et al. Photoelectrochemical performance of $\mathrm{Ag}-$ $\mathrm{TiO}_{2} /$ ITO film and Photoelectrocatalytic activity towards the oxidation of organic pollutants. Journal of Photochemistry and Photobiology A: Chemistry, 157, 1, 71-79, 2003.

HESS, T.F.; LEWIS T.A.; CRAWFORD RL, KATAMNENI, S.; WELLS, J.H. Combined photocatalytic and fungal treatment for the destruction of 2,4,6-trinitrotoluene (TNT). Water Research, 32, 5, 1481-1491, 1998.
$\mathrm{HIRSCH}, \mathrm{R}$. et al. Occurence of antibiotics in the aquatic environment. Rev. Science Total Environment; 225: 109-118, 1999.

HU, J. Y., ONG, S. L., NG, W. J., HE, B. P., LIU, W. J., FANG, Z. D., ZHANG, X. H., WANG, Z. S. Mutagenicity of polluted reservoir water and its reduction by a pilot-scale integrated biological treatment process. Bulletin of Environmental Contamination and Toxicology, 71, 1, 204-211, 2003.

JIANG, D.; et al. Kinetic Study Of Photocatalytic Oxidation Of Adsorbed Carboxylic Acids At $\mathrm{TiO}_{2}$ Porous Films By Photoelectrolysis, Journal of Catalysis, 223,1, 212-220,2004.

JOLIBOIS, B.; GUERBET, M. Evaluation of industrial, hospital and domestic wastewater genotoxicity with the Salmonella fluctuation test and the SOS chromotest. Mutation Research/Genetic Toxicology and Environmental Mutagenesis, $565,2,151-162,2005$.

JOLIBOIS, B.; GUERBET, M.; VASSAL, S. Detection of hospital wastewater genotoxicity with the SOS chromotest and Ames fluctuation test. Chemosphere, 51, 6, 539-543, 2003.

JONSSON, C.M. Fosfatase ácida da microalga Selenastrum capricornutum: extração, caracterização e efeito de poluentes de origem agrícola. Tese de Doutorado, Universidade Estadual de Campinas, Campinas, 117 p., 2005.

JORGENSEN, S. E.; HALLING-SORENSEN, B. Drugs in the environment. Chemosphere, 40 , 7, 691-699, 2000.

KAMIDA, H. M.; DURRANT, L. R.; MONTEIRO, R. T. R.; ARMAS, E.D. Biodegradation Of Textile Effluents By Pleurotus SajorCaju. Química Nova, 28, 4 , 629-632, 2005.

KAPDAN, I. K. et al. Effect of environmental conditions on biological decolorization of textile dyestuff by $T$. versicolor. Enzyme and microbial technology; 26: 381-387, 2000.

KARGALIOGLU, Y.; MCMILLAN, B. J.; MINEAR, R. A.; PLEWA, M. J. Analysis Of The Cytotoxicity And Mutagenicity Of Drinking Water Disinfection By-Products in Salmonella typhimurium. Teratogenesis Carcinogenesis and Mutagenesis, 22, 2, 113-128, 2002.

KNAPP, J. S. ; NEWBY, P. S. The microbiological decolourization of an industrial effluent containing a diazolinked chromophore. Water research; 29(7): 1807-1809, 1995.

KUMAHARA, M.; GLENN. J.K.; MORGAN, M.A.; GOLD, M.H. Separation and characterization of two extracellular $\mathrm{H}_{2} \mathrm{O}_{2}$ dependent oxidases from ligninolytic cultures of Phanerochaete chrysosporium. FEBS Lett, 169, 242-247, 1984.

KÜMMERER, K. Drugs, diagnostic agents and disinfectants in wastewater and water-a review. Rev. Schiftenr Ver Wasser Boden Lufthyg; 105, 59-71, 2000.

KÜMMERER, K.; HENNINGER, A. Promoting resistance by the emission of antibiotics from hospitals and households into effluent. Clinical Microbiology and Infection, v. 12, n. 9, p. 1203-1214, 2003.

KUNZ A.; PERALTA-ZAMORA , P.; MORAES, S. G. ; DURAN, N. Novas tendências no tratamento de efluentes têxteis, Química. Nova, 25,1, 78, 2002.

KUTLU, M.; AYDOĞAN, G.; SUSUZ, F.; ÖZATA, A. The Salmonella mutagenicity of water and sediments from the Porsuk River in Turkey. Environmental Toxicology and Pharmacology. 17,111-11, 2004. 
LÓPEZ, C., MOREIRA, M. T.,FEIJOO G., LEMA, J. M. Dye Decolorization by Manganese Peroxidase in an Enzymatic Membrane Bioreactor, Biotechnol. Prog, 20, 74-81,2004.

Mathews, R.S. Artemia salina as a test organism for measuring superoxide-mediated toxicity. Free Radical Biolical Medicine 18: 919-22, 1995.

MCLAUGHLIN, J. L.; COLMAN-SAIZARBITORIA, T.; ANDERSON, J. E. Tres bioensayos simples para quimicos de productos naturales. Revista de la Sociedad Venezolana de Química; 18, 4, 13-8, 1995.

MELO, P.S.; FABRIN-NETO, J.B.; DE MORAES, S.G.; ASSALIN, M.R., DURAN, N.; HAUN, M. Comparative toxicity of effluents processed by different treatments in V79 fibroblasts and the algae Selenastrum capricornutum. Chemosphere 62:12071213, 2006

MONARCA, S.; FERETTI, D.; COLLIVIGNARELLI, C.; GUZZELLA, L.; ZERBINI, I., BERTANZA, G.; PEDRAZZANI, R. The influence of different disinfectants on mutagenicity and toxicity of urban wastewater. Water Research, 34 ,17, 4261-4269, 2000.

MORAIS, J. L.; SIRTORI, C.; PERALTA-ZAMORA, P. G. Tratamento De Chorume De Aterro Sanitário Por Fotocatálise Heterogênea Integrada A Processo Biológico Convencional. Química Nova, 29, 20-23, 2006.

NEW, A. P. et al. Analytical techniques used for monitoring the biodegradation of flourinated compounds in waste streams from pharmaceutical production. Journal chromatografy A; 889, 1-2, 177-184, 2000.

NOGUEIRA, R.F.P.; JARDIM, W.F. A fotocatálise heterogênea e sua aplicação ambiental, Química Nova, 21,1, 69-76, 1998.

NOVOTNÝ, C. et al. Capacity of Irpex lacteus and Pleurotus ostreatus for decolorization of chemically different dyes, Journal of Biotechnology; 89, 113-122, 2001.

PALMIERI, G.; GIARINA, P; MARZULLO, L; DESIDERIO, B., NITTI, G.; CANNIO, R.; SANNIA, G. Stability and activity of phenol oxidase from Lignolytic Fungus Pleurotus ostreatus. Applied Microbiology e Biotechnology, 39, 632-636, 1993.

PARK, J. H., LEE, B. J., LEE, S. K, KIM, K., LEE, K. H., CHE, J. H., KANG, K. S., LEE, Y. S. Genotoxicity of drinking water from three Korean cities. Mutation Research/Genetic Toxicology and Environmental Mutagenesis, 466, 2, 173-178, 2000.

PARRA, S.; MALATO, S.; PULGARIN, C. New integrated photocatalytic-biological flow system using/supported $\mathrm{TiO}_{2}$ and fixed bacteria for the mineralization of isoproturon. Applied Catalysis. B. 36, 2, 131-144, 2002.

PEDROZA, A. M. ; MOSQUEdA, R.; ALONSO-VANTE, N.; RODRÍGUEZ-VÁZQUEZ, R. Sequential treatment via Trametes versicolor and $\mathrm{UV} / \mathrm{TiO}_{2} / \mathrm{Ru}(\mathrm{x}) \mathrm{Se}(\mathrm{y})$ to reduce contaminants in waste water resulting from the bleaching process during paper production. Chemosphere, 67, 4, 793-801, 2006.

PERALTA-ZAMORA, P.; KUNZ,A; MORAIS, S.G.; PELEGRINI, R.; MOLEIRO, P.C., J.REYES, DURAN, N. Degradation of reactive dyes I. A comparative study of ozonation, enzymatic and photochemical process. Chemosphere, 38, 4, 835, 1999.

PERALTA-ZAMORA, P.; MORAIS, S.G.; PELEGRINI R.; FREIRE JR, M.; REYES, J.; MANSILLA , DURAN,H., N. Evaluation of ZnO, TiO 2 and Supported $\mathrm{ZnO}$ on the Photoassisted Remediation of Black Liquor. Chemosphere , 36, 9, 2119, 1998.
PRADO, A.G.S, Química Verde, Os Desafios Da Química Do Novo Milênio, Química Nova, 26, 5, 738-744, 2003.

ROBINSON, T. et al. Remediation of dyes in textile effluent: a critical review on current treatment technologies with a proposed alternative. Bioresource technology, 77, 247-255, 2001.

SANTANA, V. S.; MACHADO, N. R. C. F. Degradação fotocatalítica de efluentes de indústria têxtil empregando $\mathrm{TiO}_{2}$ e $\mathbf{N b}_{2} \mathrm{O}_{5}$, sob irradiação visível. Acta Scientiarum Maringá, 24, 6, 1681-1686, 2002.

SANTIAGO, M. F. Estudo De Substâncias De Baixa Massa Molar Que Mimetizam As Fenoloxidases Com Aplicações Em Tratamentos De Efluentes Industriais, Tese de doutorado, Universidade Estadual de Campinas,1999.

SHISHIDA, K.; ECHIGO, S., KOSAKA, K.; TABASAKI, M.; MATSUDA, T.; TAKIGAMI, H.; YAMADA, H.; SHIMIZU, Y.; MATSUI, S. Evaluation of advanced sewage treatment processes for reuse of wastewater using bioassays. Environmental Technology, 21:5, 2000.

SILVA, A. C. Tratamento do Percolado de Aterro Sanitário e Avaliação da Toxicidade Do Efluente Bruto e Tratado. Dissertação de mestrado, Universidade Federal do Rio de Janeiro, Rio de Janeiro, 2002.

SMANIA, E. F. A.; SMANIA JUNIOR, A.; LOGUERCIO-LEITE, C. Síntese de cinabarina por Pycnoporus sanguineus e sua atividade antimicrobiana sobre bactérias isoladas de alimentos. Revista de Microbiologia, 29, 4, 317-320, 1998.

SORSA, M.; HEMMINKI, K.; VAINIO, H. Occupational exposure to anticancer drugs - Potential and real hazards. Mutation Research, 154, 135-149, 1985.

STOLZ, A. Basic and applied aspects in the microbial degradation of azo dyes -mine review. Applied Microbial Biotechnology; 56: 69-80, 2001.

SZKLARZ, G.D.; ANTIBUS, R.K.; SINSABAUGH, R.L; LINKINS, A.E. Production of phenoloxidases and peroxidases by woodrotting fungi. Mycology , 81, 234-240, 1989.

TAUCHERT, E .; PERALTA-ZAMORA, P. Avaliação De Processos Fotoeletroquímicos no Tratamento de Líquidos Lixiviados de Aterros Sanitários. Engenharia Sanitária e Ambiental, 9, 3, 197201, 2004.

TIEN, M.; KIRK, T.K. Lignin-degrading enzyme from Phanerochaete chrysosporium: purification, characterization, and catalytic properties of a unique $\mathrm{H}_{2} \mathrm{O}_{2}$-requiring oxygenase. Proceedings of the National Academy of Science. $81,2280-2284,1984$

UMBUZEIRO, G. A.: FREEMAN, H. S.; WARREN, S. H.; OLIVEIRA, D. P.; TERÃO, Y.; WATANABE, T.; CLAXTON, L. D. The contribution of azo dyes to the mutagenic activity of the Cristais River.Chemosphere 2005, 60, 55.

WEBB, S. F. A Data-based Perspective on the environmental Risk Assessment of Human Pharmaceuticals I - Collation of Available Ecotoxicity Data. Páginas 175-201 de: Kümmerer, K (ed), Pharmaceutical in the Environment: Sources, fate, effects and risks. Berlin Heidelberger New York: Springer, 2001.

WHO Consultation - World Health Organization technical report series, no 961, Geneva,1972. 
K.; MALATO, S.; WEBER, J. V. Solar photocatalytic degradation of humic acids as a model of organic compounds of landfill leachate in pilot-plant experiments: influence of inorganic salts, Applied Catalysis, B. V. 53, p. 127-137, 2004.

YOUNG, L.; YU, J. Ligninase-catalysed decolorization of synthetic dyes. Water research, 31(5), 1187-1193, 1997.

ZIOLLI, R. L.; JARDIM, W. F. Mecanismo de Fotodegradação e Compostos Orgânicos Catalisada Por $\mathrm{TiO}_{2}$, Química Nova, 21, 3, 319-325, 1998. 